\title{
UUCG RNA tetraloop as a formidable force-field challenge for MD simulations
}

\author{
Klaudia Mráziková, Vojtěch Mlýnský, Petra Kührová, Pavlína Pokorná, Holger Kruse, Miroslav \\ Krepl, Michal Otyepka, Pavel Banáš, and Jiři Šponer
}

Table of Contents

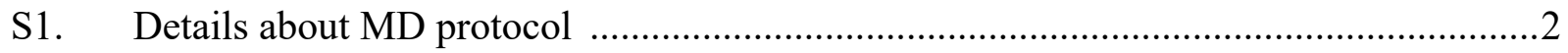

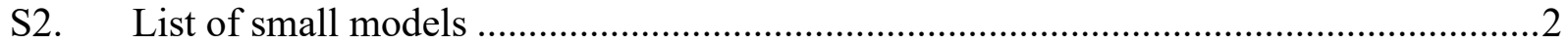

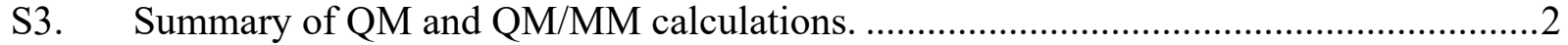

S4. Additional computational details of small models .......................................................

S5. Comment on the comparison of 2'-OH group conformational scans...........................6

S6. MD Simulations and QM/MM and MM optimizations of the kink-turn Kt-7 .............6

S7. Large-scale implicit solvent QM calculations ........................................................

S8. Relationship between $\mathrm{G}_{\mathrm{S}+1}$ phosphate conformation and $\mathrm{G}_{\mathrm{L} 4}$ nucleotide ................... 8

S9. Details about folding of the gcUUCGgc TL using the gHBfix potential.....................9

S10. Details about geometry restraints of the $\mathrm{U}_{\mathrm{L} 1}\left(2^{\prime}-\mathrm{OH}\right)$ dihedral .................................. 9

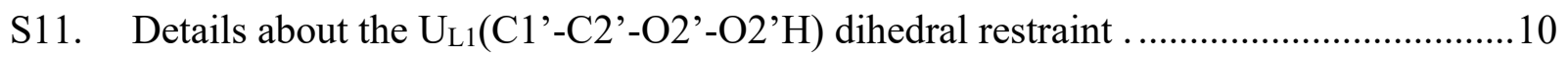

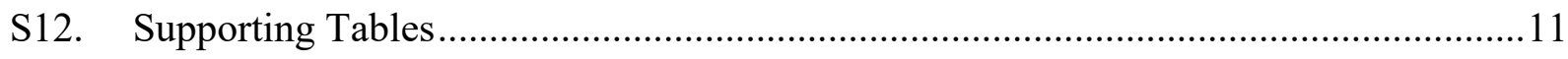

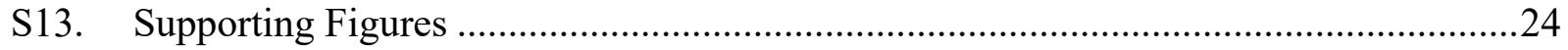

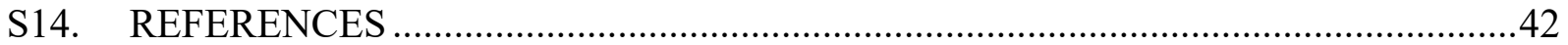


S1. Details about MD protocol. The minimum distance between box walls and solute was $12 \AA$. The RNA molecule remained constrained during energy minimization of water and ions. Subsequently, all RNA atoms were frozen and the solvent molecules with counter-ions were allowed to move during a 500-ps long MD run under NpT conditions ( $\mathrm{p}=1 \mathrm{~atm} ., \mathrm{T}=298.16 \mathrm{~K}$ ) in order to relax the total density. After this, the RNA molecule was relaxed by several minimization runs, with decreasing force constant applied to the sugar-phosphate backbone atoms. Subsequently, the system was heated in two steps: the first step involved heating under NVT conditions for $100 \mathrm{ps}$, whereas the second step involved density equilibration under NpT conditions for additional 100 ps. The particle mesh Ewald (PME) method for treating electrostatic interactions was used. The standard unbiased MD simulations were performed under periodic boundary conditions in the $\mathrm{NpT}$ ensemble at $298.16 \mathrm{~K}$ using weak-coupling Berendsen thermostat ${ }^{1}$ with coupling time of $1 \mathrm{ps}$. The SHAKE algorithm, with a tolerance of $10^{-5} \AA$, was used to fix the positions of all hydrogen atoms, and a $10.0 \AA$ cut-off was applied to non-bonding interactions to allow a 2 -fs integration step.

\section{S2. List of small models}

Figure S5 Dinucleoside monophosphates

Figure S6 A - Dimethyl-phosphate - methyl-guanine

B - O3'-methylated-guanosine-monophosphate

C - guanine-ribose $\left(170^{\circ}\right)$

D - guanine-ribose $\left(143^{\circ}\right)$

E - ribose-base stacking model

Figure S10 Optimized U $\mathrm{L}_{2} \mathrm{C}_{2}$ '-endo ribose model

S3. Summary of $\mathbf{Q M}$ and $\mathbf{Q M} / \mathbf{M M}$ calculations. We performed 85 explicit solvent QM/MM geometry optimizations of UUCG RNA TLs using either r(acUUCGgu) or r(gcUUCGgc) 8-mers. QM regions included whole RNA TL, i.e., 252 and 254 atoms for $\mathrm{r}(\mathrm{acUUCGgu})$ and $\mathrm{r}(\mathrm{gcUUCG} \mathrm{Cgc})$ sequences, respectively. MM regions contained counter ions and explicit water molecules ( $\sim 25000$ atoms in total). DFT-D3 method with PBEh-3c functional and def2-mSVP basis set was used. Among those QM/MM optimizations, 29 were performed without any geometry restraints and 56 contained restraints applied on the $\mathrm{U}_{\mathrm{L} 1}(\mathrm{C} 1$ '-C2'-O2'$\left.\mathrm{O} 2{ }^{\prime} \mathrm{H}\right)$ dihedral. Note that one QM/MM optimization without geometry restraints ( $\sim 600$ steps) took $\sim 9$ days using $162.6 \mathrm{GHz}$ E5-2640v3 Xeon CPU cores. We also performed $8 \mathrm{QM}$ optimizations of UUCG TL using COSMO implicit solvent. All QM/MM optimizations were mirrored by equivalent $\mathrm{MM}$ calculations.

Other sets of QM calculations were performed on small model systems. We performed 8 QM optimizations in COSMO implicit solvent of dinucleoside monophosphate models, half as free optimizations and half with restraints on backbone dihedrals. Finally, we calculated 14 QM interaction or conformational energy scans on seven different small models (dimethylphosphate-methyl-guanine, O3'-methylated-guanosine-monophosphate, H-bonded guanineribose with $170^{\circ}$ angle, $\mathrm{H}$-bonded guanine-ribose with $143^{\circ}$ angle, ribose, perpendicularly stacked ribose-guanine and perpendicularly stacked truncated ribose-guanine; 278 points altogether). Among those, 8 were done using PBEh-3c hybrid DFT functional (157 points) and 6 with highly accurate (used as reference here) DLPNO-CCSD(T)/CBS method (121 points). 


\section{S4. Additional computational details of small models QM and MM geometry optimizations of dinucleoside monophosphate models}

Dinucleoside monophosphate models were cut from the four representative snapshots of MD simulation, i.e., the snapshots which include the four substates of the $\mathrm{G}_{\mathrm{L} 4}$ nucleotide and $\mathrm{G}_{\mathrm{S}+1}$ phosphate as discussed in the main text. We performed QM (PBEh-3c) and MM (ff99bsc0 $\chi_{\mathrm{OL} 3 \mathrm{CP} \text {; }}$ see Methods in the main text) geometry optimizations of these dinucleoside monophosphate models (Figure S5). We aimed to compare the characteristic combinations of $\mathrm{G}_{\mathrm{L} 4}$ nucleobase position and $\mathrm{G}_{\mathrm{S}+1}$ phosphate conformation (planar-native, tilted-native, planar-flipped or tiltedflipped), i.e., the energy differences among these states. QM and MM geometry optimizations either in gas phase or with implicit solvent $\left(\mathrm{COSMO}^{2}\right.$ and $\mathrm{GB}^{3,4}$ for $\mathrm{QM}$ and MM, respectively) were performed using $X o p t^{5,6}$ coupled with TURBOMOLE V7.3 $3^{7,8}$ (QM) or AMBER $14^{9}$ (MM). Dihedral restraints include backbone dihedrals $\alpha, \beta, \gamma, \delta, \varepsilon, \zeta$ and $\chi$, ribose dihedrals $v_{0}, v_{3}, v_{4}$, and C4'-C3'-C2'-O2', and base dihedrals C5-N7-C8-N9, C6- C5-N7-C8, N1-C6-C5-N7, C2-N1-C6C5, N3-C2-N1-C6, N1-C2-N3-C4, C2-N3-C4-N9, C2-N1-C6-O6 and N2-C2-N3-C4 with the restraining constant equal to $0.1 \mathrm{E}_{\mathrm{h}} \cdot \mathrm{rad}^{-2}$. Use of tight restraints instead of the common constraints in QM optimizations provides residual flexibility which helps to correctly relax complex biomolecular building blocks. ${ }^{5,6}$ Results are shown in Table S6.

\section{Energy scans describing the $0 B P h$ interaction}

Dimethyl-phosphate - methyl-guanine intermolecular complex

Small model of dimethyl-phosphate - methyl-guanine (Figure S6A) was extracted from QM/MM-optimized geometry of structure 6e (native $\mathrm{G}_{\mathrm{S}+1}$ phosphate). The missing hydrogens were added by hand and the whole geometry was optimized at the PBEh-3c level using angle and dihedral restraints with the restraining constant equal to 1.0 and $0.1 \mathrm{E}_{\mathrm{h}} \cdot \mathrm{rad}^{-2}$, respectively (O5'H8-C8 and C5'-O5'-H8 angles, and C3'-O3'-P-O5', O3'-P-O5'-C5', C3'-O3'-C6-N1, C5'-O5'C8-N9 and O5'-P-C5-C4 dihedrals). Then, we performed a rigid-monomers QM (PBEh-3c) interaction-energy scan along the $\mathrm{C} 8 \mathrm{H} 8 \ldots \mathrm{O} 5$ ' vector with step length $0.05 \AA$ in range of 2.10 $2.60 \AA$. The $b f f^{10}$ program was then used to perform two MM interaction-energy scans with rigid monomers (using non-bonding terms of AMBER $f f$ with the vdW modification of phosphate oxygens) using the same geometries. Partial charges were taken from AMBER 16 library files and the partial charges of methyl hydrogens were set to a value of 0.04248 to obtain a molecular charge equal to -1 . One of the MM scans includes NBfix correction applied to the $-\mathrm{H} 8 \ldots \mathrm{O} 5^{\prime}-$ Lennard-Jones pair. The $R_{i, j}$ parameter for H5 and OR atom types was set to a value of $2.8808 \AA$, while the $e_{i, j}$ parameter was kept at its default value of $0.0505 \mathrm{kcal} / \mathrm{mol}$. Reference QM calculations at the DLPNO-CCSD(T)/CBS level were performed at C8H8...O5' distances of $2.10,2.20,2.30,2.40$ and $2.50 \AA$.

\section{O3'-methylated-guanosine-monophosphate monomer}

The O3'-methylated-guanosine-monophosphate model (Figure S6B) was extracted from QM/MM optimized geometry of structure 6 e (native $\mathrm{G}_{\mathrm{S}+1}$ phosphate) and the missing hydrogens 
were added by hand. Gaussian $09^{11}$ was used for relaxed MM (ff $99 \mathrm{bsc} 0 \chi_{\mathrm{OL} 3 \mathrm{CP}}$ ) conformation energy scan along the $\mathrm{C} 8 \mathrm{H} 8$... O5' distance in range of 2.05-2.60 $\AA$ with step length of $0.05 \AA$. Geometry constraints were applied on $\mathrm{G}_{\mathrm{S}+1}(\mathrm{C} 8)-\mathrm{G}_{\mathrm{S}+1}(\mathrm{H} 8)-\mathrm{G}_{\mathrm{S}+1}\left(\mathrm{O} 5{ }^{\prime}\right)$ angle, and $\mathrm{G}_{\mathrm{L} 4}\left(\mathrm{C} 3^{\prime}\right)$ $\mathrm{G}_{\mathrm{L} 4}\left(\mathrm{O}^{\prime}\right)^{\prime}-\mathrm{G}_{\mathrm{S}+1}\left(\mathrm{C}^{\prime}\right)-\mathrm{G}_{\mathrm{S}+1}\left(\mathrm{C}^{\prime}{ }^{\prime}\right)$ and $\mathrm{G}_{\mathrm{L} 4}\left(\mathrm{C}^{\prime}\right)-\mathrm{G}_{\mathrm{S}+1}\left(\mathrm{C}^{\prime}\right)-\mathrm{G}_{\mathrm{S}+1}\left(\mathrm{C} 2^{\prime}\right)-\mathrm{G}_{\mathrm{S}+1}(\mathrm{C} 4)$ dihedrals. Partial charges were taken from AMBER 16 library files and the partial charges of hydroxyl oxygens were modified, i.e., O3' $\mathrm{H}$ from 0.43760 to 0.3525 and $\mathrm{O} 2$ ' $\mathrm{H}$ from 0.41860 to 0.3335 , in order to obtain a molecular charge equal to -1 . Then, we also performed QM (PBEh-3c) single point calculations on the MM-optimized geometries.

\section{Energy scans describing the $U_{L 2}\left(2^{\prime}-O H\right) \ldots G_{L 4}(N 7) H$-bond}

A small guanine-ribose model was extracted from the initial geometry of structure 1. Two different guanine-ribose models were prepared for interaction energy scans using the following geometry optimizations.

Both models were optimized by QM (PBEh-3c) in gas phase using Xopt with geometrical restraints to keep the correct orientation of monomers representing $\mathrm{U}_{\mathrm{L} 2}$ ribose and $\mathrm{G}_{\mathrm{L} 4}$ base. The geometrical restraints were applied on 11 dihedrals (ribose dihedrals $v_{0}$ and $v_{3}$, backbone dihedrals $\gamma$ and $\delta$, C4'-C5'-O5'-O5'H, C5'-O5'-O5'H-C6, O5'-O5'H-N1-C6, C4'-C3'-O3'O3'H, C8-C3'-O3'-O3'H, N9-C8-O3'-O3'H and C4'-C3'-C5-C4) using restraining constant equal to $0.1 \mathrm{E}_{\mathrm{h}} \cdot \mathrm{rad}^{-2}$. O2'-O2'H-N7 angle (representing the $\mathrm{U}_{\mathrm{L} 2}\left(\mathrm{O} 2{ }^{\prime}\right)-\mathrm{U}_{\mathrm{L} 2}\left(\mathrm{O} 2{ }^{\prime} \mathrm{H}\right)-\mathrm{G}_{\mathrm{L} 4}(\mathrm{~N} 7)$ angle) was equal to $170^{\circ}$ after the optimization of the first model. For the second guanine-ribose model, an additional geometrical restraint with the restraining constant equal to $0.1 \mathrm{E}_{\mathrm{h}} \cdot \mathrm{rad}^{-2}$ was applied on the $2^{\prime}$ '-O2'H-N7 angle in order to keep it at $143^{\circ}$, i.e., to maintain the lower directionality of the $\mathrm{U}_{\mathrm{L} 2}\left(2^{\prime}-\mathrm{OH}\right) \ldots \mathrm{G}_{\mathrm{L} 4}(\mathrm{~N} 7) \mathrm{H}$-bond often found in $\mathrm{MD}$ simulations. Interaction-energy scans along the $\mathrm{O} 2$ '...N7 vector were then performed with step length of $0.05 \AA$ in range of $2.65-$ $3.15 \AA$ for $\mathrm{QM}(\mathrm{PBEh}-3 \mathrm{c})$ and $\mathrm{MM}$ (AMBER $f f)$, and in range of $2.70-3.10 \AA$ for $\mathrm{QM}$ reference (DLPNO-CCSD(T)/CBS).

\section{Geometry optimizations and energy scans of the $U_{L 2}$ ribose}

The ribose model was excised from the initial geometry of structure 9. The missing $\mathrm{H}$ atoms were added by hand to the $\mathrm{O}^{\prime}$ '- and $\mathrm{O} 3$ '-end. Then, the model was optimized by QM (PBEh-3c) or $\mathrm{MM}\left(f f 99 \mathrm{bsc} 0_{\mathrm{CP}}\right)$ in gas phase. For QM optimization, Xopt was used with geometrical restraints on two dihedrals ( $\mathrm{C}^{\prime}$ '-C5'-O5' $-\mathrm{O} 5^{\prime} \mathrm{H}$ and $\mathrm{C}^{\prime}$ '-C3'-O3'-O3' $\mathrm{H}$ ) with restraining constant equal to $0.1 \mathrm{E}_{\mathrm{h}} \cdot \mathrm{rad}^{-2}$ to keep the $\mathrm{C} 2$ '-endo pucker of the $\mathrm{U}_{\mathrm{L} 2}$ ribose. For $\mathrm{MM}$ optimization, Gaussian 09 with geometrical constraints on the same two dihedrals (C4'-C5'-O5'$\mathrm{O} 5$ ' $\mathrm{H}$ and $\mathrm{C} 4$ '-C3'-O3'-O3' $\mathrm{H}$ ) was used while the LJ parameters and partial charges were taken from AMBER 16 library files. Two rigid conformation energy scans were performed on QMoptimized ribose, i.e. bending of the C2'-O2'-O2' $\mathrm{H}$ angle and rotation of the $\mathrm{C} 1$ '- $\mathrm{C} 2$ '-O2'-O2'H dihedral using $\mathrm{MM}\left(f f 99 \mathrm{bsc} 0_{\mathrm{CP}}\right), \mathrm{QM}(\mathrm{PBEh}-3 \mathrm{c})$ and $\mathrm{QM}$ reference (DLPNO-CCSD(T)/CBS) calculations. For MM optimization and single point calculations the partial charges were taken from nucleic10.in file, i.e., parameters for r-uracil with 5'-phosphate group and 3'- $\mathrm{O}^{-}$group, and the partial charges of the capping 5'- and 3'-end hydrogen atoms were set to value 0.1490 to obtain a neutral charge of the ribose. The $\mathrm{H} 1$ ', hydrogen atom was assigned by $\mathrm{H} 2$ atom type to 
be equal to the $\mathrm{H} 1$ ' atom and the $\mathrm{H} 2-\mathrm{CT}-\mathrm{H} 2$ angle parameters were set to be equal to $\mathrm{H} 1-\mathrm{CI}-\mathrm{H} 1$ angle parameters. The OR-HO bond parameters were set to $\mathrm{OH}-\mathrm{HO}$ bond parameters, and the CT-OR-HO and CI-OR-HO angle parameters were set to be equal to CT-OR-P and CI-OR-P angle parameters.

\section{Energy scans describing ribose-base stacking}

A small ribose-guanine model for the stacking interaction (Figure S6E) was extracted from QM/MM-optimized geometry of structure 9e. The model was optimized by QM (PBEh-3c) in gas phase using the Xopt program in the following way. Atoms of both monomers (except hydrogens and hydroxyl groups) were frozen during the optimization in order to keep the correct C2'-endo pucker of the $\mathrm{C}_{\mathrm{L} 3}$ ribose and the mutual orientation of the $\mathrm{C}_{\mathrm{L} 3}$ ribose and $\mathrm{G}_{\mathrm{L} 4}$ base. Geometrical restraints were applied on three dihedrals involving the hydroxyl groups, i.e. O5'HO5'-C5'-C4' (pseudo $\beta$ ), C4'-C3'-O3'-O3'H (pseudo $\varepsilon$ ) and $\mathrm{C} 1$ '-C2'-O2'-O2'H dihedrals, using restraining constant equal to $0.1 \mathrm{E}_{\mathrm{h}} \cdot \mathrm{rad}^{-2}$ to keep the correct orientation of hydroxyl groups. Interaction energy scans were performed along the vector lying on the vertical axis linking the projection point of the O4' atom on the guanine plane and the O4' atom itself. Subsequently, interaction energies were calculated in range from $2.5-3.4 \AA$ of the $\mathrm{O} 4$ ' - guanine distance, i.e., distance between the O4' atom and the guanine plane, with the step length of $0.1 \AA$. The PBEh3c (QM), AMBER ff (MM) and DLPNO-CCSD(T) (QM reference) methods were used for energy calculations. Partial charges for MM calculations were derived as restrained electrostatic potential fit (RESP) ${ }^{12}$ procedure by Antechamber. ${ }^{13}$ Two types of RESP charges were used, i.e., AMBER-like partial charges derived from HF/6-31G* ESP (RESP-HF) and partial charges derived from B3LYP/def2-QZVP ESP (RESP-B3LYP). ESPs were computed with tight SCF setting using the Merz-Singh-Kollman population analysis by Gaussian 09. LJ parameters were taken from AMBER 16 library file nucleic10.in, i.e., parameters for r-cytosine with 5'-phosphate group and 3 ' $-\mathrm{O}^{-}$group for ribose and r-guanosine with 5 '-phosphate group and 3 ' $-\mathrm{O}^{-}$group for guanine. The capping hydrogen atom on N9 atom of guanine was assigned by $\mathrm{H}$ atom type and the capping hydrogens on 3'- and 5'-end were assigned as $\mathrm{HO}$ atom types.

In addition, we provide the interaction energy scan using the PBEh-3c method with truncated ribose, i.e., using similar model as used in ref. ${ }^{14}$. The model using the truncated ribose was prepared by replacing the hydroxy and hydroxymethyl group on C2' and C4' atoms, respectively, with $\mathrm{H}$ atoms. Then, positions of $\mathrm{H}$ atoms bound to $\mathrm{C}$ atoms were optimized using the PBEh-3c method and the Xopt program. Interaction energies were, again, calculated in range

from 2.5-3.4 $\AA$ of the O4'-guanine distance with the step length of $0.1 \AA$. 
S5. Comment on the comparison of 2'-OH group conformational scans using either $\mathbf{U}_{\mathbf{L} 2}$ ribose or SPS model. We performed gas phase conformation energy scans of the $\mathrm{U}_{\mathrm{L} 2}(\mathrm{C} 1$ '-C2'$\mathrm{O} 2$ '-O2'H) dihedral using $\mathrm{C}^{\prime}$ '-endo ribose model and found that results are in agreement with conformation energy scans of the 2'-OH group rotation performed earlier by our group using the sugar-to-sugar (SPS) model (see ref. ${ }^{15}$ ). In the earlier study, the C3'-C2'-O2'-O2'H dihedral was analyzed using the gas phase and implicit solvent QM and MM calculations for various conformational families ${ }^{16}$ of the SPS model. ${ }^{15}$ We chose scans performed for 2 [ conformational family for a comparison with our scan since the $\mathrm{U}_{\mathrm{L} 2}-\mathrm{C}_{\mathrm{L} 3}$ dinucleotide of the UUCG TL possesses the same conformational family. ${ }^{16}$ Firstly, we compare the two conformational scans performed in gas phase, i.e. our ribose scan (Figure 7 in the main text) and the earlier SPS scan (see Figure S1 in the Supporting information of ref. ${ }^{15}$ ). Obviously, use of different models causes some differences between the two scans, i.e., QM energy is steeply descending towards the $260^{\circ}$ in the SPS scan instead of finding a very flat QM minimum observed by our ribose scan. However, the steepness is still smaller compared to MM. Furthermore, in the SPS scans with implicit solvent (see Figure 6 of ref. ${ }^{15}$ ) MM finds a local minimum in the region of our interest, i.e. C1'-C2'$\mathrm{O} 2$ ' $-\mathrm{O} 2$ ' $\mathrm{H}$ dihedral values between $\sim 170^{\circ}$ and $\sim 200^{\circ}$, which corresponds to the $\mathrm{C} 3$ '-C2'-O2'$\mathrm{O} 2^{\prime} \mathrm{H}$ dihedral region between $\sim 290^{\circ}$ and $\sim 320^{\circ}$. However, the QM energy is increasing in the same region indicating that a shift of the dihedral towards larger values is unlikely. In contrast, shifting of the dihedral towards larger or smaller values on the quite symmetric local minimum of the MM scan indicates no preference for any of the directions. Taking all together, all these conformation energy scans, i.e. the new scans on the C2'-endo ribose model present in this study and the earlier scans on the SPS model, ${ }^{15}$ show a difference in MM and QM description of the $\mathrm{C} 1$ '-C2'-O2'-O2' $\mathrm{H}$ dihedral in the region of our interest suggesting that $\mathrm{MM}$ is prone to shifting the $\mathrm{C} 1$ '-C2'-O2'-O2'H dihedral towards larger values more than QM. Obviously, as all calculations are done on small model systems, the results should not be over-interpreted.

S6. MD Simulations and QM/MM and MM optimizations of the kink-turn Kt-7. The sequence of the kink-turn 7 (Kt-7) from $\mathrm{H}$. marismortui ribosome is close to the consensual sequence shared by all kink-turns. ${ }^{17} \mathrm{Kt}-7$ is thus a useful model for studying the behavior of this recurrent RNA motif in calculations. Structurally, the kink-turn structure facilitates a sharp, almost perpendicular bend (kink), between two A-RNA helices. It is composed of canonical and non-canonical stems, and a bulge. The non-canonical stem contains conserved transHoogsteen/sugar-edge A/G base pairs. The bent shape of the kink-turn structure is stabilized by an A-minor RNA tertiary interaction in which the adenine base from one of the A/G base pairs of the non-canonical stem makes contacts with the minor groove of the canonical stem. Furthermore, another adenine from the non-canonical stem forms a characteristic interaction with the first nucleotide of the bulge. The multitude of non-canonical but critically important interactions makes the kink-turn an ideal structure for benchmarking $f f$ performance. ${ }^{18}$

Here, we focused our attention on two hydrogen bond interactions in which the 2-OH' hydroxyl group of the ribose is acting as H-bond donor towards a base nitrogen. To simplify the presentation, we denote these H-bonds as HB1 and HB2, respectively. We show in this work (see the main text) that for the UUCG TL, comparison with the QM/MM calculations reveals excessive non-planarity predicted by the ff for a key H-bond involving the 2-OH' hydroxyl group as a donor and nitrogen of the base as acceptor. Note that the acceptor atom in the UUCG Hbond is N7 while the HB1 and HB2 interactions involve the N1 atom. However, both of these 
atoms are described by the same vdW parameter in the $f f$ and may thus be affected by similar issues.

We first performed five MD simulations of the Kt-7, each five microseconds long. The simulations indicated a generally satisfactory performance with the standard RNA force field ff $99 \mathrm{bsc} 0 \chi_{\mathrm{OL} 3}$ in combination with the SPC/E water model. Namely, the kink-turn maintained its bent shape and characteristic non-canonical interactions in all simulations, including the HB1 and HB2 H-bonds. The exception was two simulations in which we observed permanent transition from the A-minor I type of interaction towards the A-minor 0. This transition can be commonly observed in MD simulations of isolated kink-turns as both A-minor interactions are, in principle, possible for the kink-turn structure. ${ }^{19,20} \mathrm{We}$ subsequently selected three snapshots from the simulation ensemble and performed QM/MM and $\mathrm{MM}$ optimizations of these structures. As shown in Table S11, the QM/MM did not, in this case, reveal any problem with non-planarity comparable to the one seen for the UUCG TL. The interaction angle indicated by the MM was comparable with the QM/MM values.

\section{Computational details about QM/MM and MM optimizations of Kt-7}

The three MD snapshots (denoted as structures 1, 2 and 3) chosen for the QM/MM and MM optimizations of $\mathrm{Kt}-7$ were solvated by water droplet with radius of $\sim 40 \AA$ from the center of RNA using SPC/E model and by $17 \mathrm{~K}^{+}$ions to neutralize the RNA using the tLEaP module of AMBER 16 software package. Then, equilibrations of water and ions ( $>15 \mathrm{ps})$ were performed to relax positions of solvent molecules and to obtain a solvent distribution with the ions distributed at least $5 \AA$ far from the QM region (structures 1a, 2a and 3a). For two of the three solvent-equilibrated MD snapshots (structures 2 and 3), another two snapshots were prepared for QM/MM and MM optimizations, i.e., structures with 60 ps and 100 ps-long water equilibrations (denoted as $\mathbf{b}$ and $\mathbf{c}$ ). The whole RNA except of the two base pairs at the end of the canonical stem and one base pair at the end of the non-canonical stem was included in the QM region. All the other atoms including water and ions were included in the $\mathrm{MM}$ region. At the QM/MM interface the C4'-C5' bonds were cut, and the remaining carbon atoms were capped by hydrogen link atoms. The QM/MM and MM optimizations were performed as described in the main text without usage of the $\mathrm{CP}$ van der Waals correction for any of the structures. 
S7. Large-scale implicit solvent $\mathbf{Q M}$ calculations. In addition to $\mathrm{QM} / \mathrm{MM}$ and $\mathrm{MM}$ calculations performed in the explicit solvent, we also tested the effect of implicit solvation for QM and MM geometry optimizations of the r(gcUUCGgc) TL. We used the COSMO implicit solvent at the QM level. The QM/COSMO computations are compared with equivalent MM/GB computations. We optimized multiple structural states and observed that the $\mathrm{G}_{\mathrm{S}+1}(\mathrm{C} 8 \mathrm{H} 8) \ldots \mathrm{G}_{\mathrm{S}+1}\left(\mathrm{O}^{\prime}\right)$ ) $0 \mathrm{BPh}$ interaction is described differently by the QM and MM approaches (distance difference of $\sim 0.12 \AA$, Table S14). We also identified that both signature sugar-base H-bonds, i.e., $\mathrm{U}_{\mathrm{L} 2}\left(2^{\prime}\right.$ '-OH $) \ldots \mathrm{G}_{\mathrm{L} 4}(\mathrm{~N} 7)$ and $\mathrm{U}_{\mathrm{L} 1}\left(2^{\prime}-\mathrm{OH}\right) \ldots \mathrm{G}_{\mathrm{L} 4}(\mathrm{O} 6)$, are weakened by MM. The former one is weakened within MM by the decreased O-H...N angle (by $\sim 28^{\circ}$ ). The latter one revealed prolonged donor-acceptor $\mathrm{U}_{\mathrm{L} 1}\left(\mathrm{O}_{2}^{\prime}\right) \ldots \mathrm{G}_{\mathrm{L} 4}(\mathrm{O} 6)$ and hydrogen-acceptor $\mathrm{U}_{\mathrm{L} 1}\left(\mathrm{O} 2^{\prime} \mathrm{H}\right) \ldots \mathrm{G}_{\mathrm{L} 4}(\mathrm{O} 6)$ distances (by $\sim 0.04 \AA$ and $0.03 \AA$, respectively) in MM-optimized TLs in comparison with QM-optimized TLs. Interestingly, MM-optimized geometries indicate that the $\mathrm{G}_{\mathrm{L} 4}$ nucleotide prefers the planar conformation, whereas QM optimizations revealed tilted states (Table S15 and Figure S5). Such a behavior could be connected to the already known overstabilization of stacking by current RNA $f f \mathrm{~s}^{21-23}$ The tendency of MM to support planar position of the $\mathrm{G}_{\mathrm{L} 4}$ nucleotide is, probably, further weakening the wrongly described $\mathrm{U}_{\mathrm{L} 2}\left(2^{\prime}\right.$ '$\mathrm{OH}) \ldots \mathrm{G}_{\mathrm{L} 4}(\mathrm{~N} 7)$ and $\mathrm{U}_{\mathrm{L} 1}\left(2^{\prime}\right.$ '-OH $) \ldots \mathrm{G}_{\mathrm{L} 4}(\mathrm{O} 6) \mathrm{H}$-bonds. The result is consistent with the QM/MM and $\mathrm{MM}$ explicit-solvent investigations discussed in the main text. Note that implicit solvent optimizations resulted (in some optimizations) into formation of spurious molecular interactions and such structures were excluded from the analysis. Similar problems in continuum-solvent optimization of larger nucleic acids models were discussed by us elsewhere, where we have tried large-scale QM optimization of nucleic acids building blocks. ${ }^{24}$ Generally, we assume that the $\mathrm{QM} / \mathrm{MM}$ approach is more representative than the QM/COSMO approach for the purpose of this study, though all approaches provide a consistent picture.

S8. Details about the relationship between $\mathbf{G}_{\mathrm{S}+\mathbf{1}}$ phosphate conformation and positioning of the $\mathbf{G}_{\mathbf{L} 4}$ nucleotide. The primary NMR data ${ }^{25}$ is consistent with two marginally different conformations (states) of the $\mathrm{G}_{\mathrm{L} 4}$ syn nucleotide, namely a planar state with parallel position to the plane formed by the closing $\mathrm{G}_{\mathrm{S}+1} \mathrm{C}_{\mathrm{S}-1}$ base pair or a slightly tilted state (Figure S5). Based on the visual inspection of MD snapshots, we suspected that the $\mathrm{G}_{\mathrm{L} 4}$ conformation (planar or tilted) could be related to $\mathrm{G}_{\mathrm{S}+1}$ phosphate flipping. Thus, we analyzed correlation between the $\mathrm{G}_{\mathrm{L} 4}$ position and conformations of the $\mathrm{G}_{\mathrm{S}+1}$ phosphate and found that all $\mathrm{G}_{\mathrm{L} 4-\mathrm{G}_{\mathrm{S}+1}}$ substates, i.e. having native/flipped $\mathrm{G}_{\mathrm{S}+1}$ phosphate state combined with planar/tilted $\mathrm{G}_{\mathrm{L} 4}$ conformation, were populated during MD simulations (Figure S8). However, it is difficult to differentiate between planar and tilted conformation of the $\mathrm{G}_{\mathrm{L} 4}$ nucleotide during $\mathrm{MD}$ simulations due to smooth fluctuations between them (angle between planes in the range $\sim 10^{\circ}$ and $\sim 30^{\circ}$, respectively, see Methods in the main text for details about the angle analysis).

In order to get insights into the ff performance, we carried out a series of QM investigations. We extracted the dinucleoside monophosphate model (containing the $\mathrm{G}_{\mathrm{L} 4}$ nucleotide and the $\mathrm{G}_{\mathrm{S}+1}$ phosphate; Figure S5) out of the UUCG TL structure. We compared QM and MM relative potential energies of the four major conformational states of the $\mathrm{G}_{\mathrm{L} 4}$ nucleotide - $\mathrm{G}_{\mathrm{S}+1}$ phosphate motif, i.e., planar-native, planar-flipped, tilted-native, and tilted-flipped (see Section $\mathbf{S} 4$ for computational details). The idea to use this simple model was to exclude additional structural constraints coming from neighboring nucleotides and from the sugar-phosphate backbone. Both QM and MM indicate that native $\mathrm{G}_{\mathrm{S}+1}$ phosphate state is preferred independently on the $\mathrm{G}_{\mathrm{L} 4}$ conformation (Table S6). However, native $\mathrm{G}_{\mathrm{S}+1}$ phosphate appears to favor planar $\mathrm{G}_{\mathrm{L} 4}$ 
conformation in MM, which is in contrast with the QM description that has no preference (Table S6).

In summary, the analysis indicates that the native state of $\mathrm{G}_{\mathrm{S}+1}$ phosphate could drive $\mathrm{G}_{\mathrm{L} 4}$ nucleotide to the planar conformation during MD simulations (due to its overstabilization within $\mathrm{MM}$ in comparison with the QM method). This conformation is prone to weakening of the signature $\mathrm{U}_{\mathrm{L} 2}\left(2\right.$ '-OH)... G $\mathrm{L}_{4}(\mathrm{~N} 7)$ sugar-base H-bond (Figure S9). In MD simulations, we did not see any correlation between position of the $\mathrm{G}_{\mathrm{L} 4}$ nucleotide and the $\mathrm{G}_{\mathrm{S}+1}$ phosphate conformation (Figure S8).

S9. Details about folding of the geUUCGgc TL using the gHBfix potential. In our previous work we have shown that the $\chi_{\mathrm{OL} 3 \mathrm{CP}}+$ gHBfix 19 ff version generally improves RNA simulations without side-effects, though it was still not sufficient to fold the UUCG TL. ${ }^{18}$

We have then tried several additional gHBfix settings to specifically improve folding of the gcUUCGgc 8-mer. Support of sugar-base interactions appears necessary, as it targets important UNCG signature interactions. gHBfix 19 modified by additional strengthening of sugar-base donor-acceptor interactions (i.e., $-\mathrm{OH}$... $\mathrm{N}-$ and $-\mathrm{OH}$... $\mathrm{O}-\mathrm{H}$-bonds) by $0.5 \mathrm{kcal} / \mathrm{mol}$ increased the population of structures with correctly folded A-form stem to $\sim 70 \% .{ }^{18}$ However, the TL was still not properly structured, as, among other things, some other non-native sugar-base interactions occurred. Thus, we tried to further weaken base-sugar donor - acceptor (i.e., $\mathrm{NH} . . \mathrm{O} 2^{\prime}-$ ) and sugar-sugar (i.e., $-\mathrm{OH} . . \mathrm{O} 4^{\prime}-$ and $-\mathrm{OH} . . \mathrm{OH}-$ ) interactions (both by $0.5 \mathrm{kcal} / \mathrm{mol})$. This resulted in a complex variant marked as $\operatorname{gHBfix}\left(\begin{array}{c}2-\mathrm{OH} \ldots \mathrm{nbO} / \mathrm{bO} \\ -0.5\end{array}\right)\left(\begin{array}{c}\mathrm{NH} \ldots \mathrm{N} \\ +0.5\end{array}\right)\left(\begin{array}{c}\mathrm{NH} \ldots \mathrm{O} \\ +0.5\end{array}\right)\left(\begin{array}{c}2-\mathrm{OH} \ldots \mathrm{N} / \mathrm{O} \\ +0.5\end{array}\right)\left(\begin{array}{c}\mathrm{NH} \ldots \mathrm{O} 2 \\ -0.5\end{array}\right)\left(\begin{array}{c}2-\mathrm{OH} \ldots \mathrm{O} 2 / \mathrm{O} 4 \\ -0.5\end{array}\right)$ when using notation of the original gHBfix paper. ${ }^{18}$ For the sake of clarity, Table S16 shows full list of all interactions affected by this modification which is abbreviated as gHBfixunCG19.

With the gHBfixunCG19 variant, population of the stem dropped to just $\sim 12 \%$, which is probably caused by some undesired side-effects within the unfolded ensemble. However, the overall population of fully correct UUCG TL was $\sim 5 \%$ in the reference replica of the $10 \mu$ s-long REST2 simulation. Considering possible convergence uncertainties of REST2 simulations, ${ }^{18}$ we now prolonged the REST2 simulation towards $20 \mu$ s but we did not observe another complete folding event (both stem and loop correctly folded, Figure S19).

S10. Details about geometry restraints of the $\mathrm{U}_{\mathrm{L1}}\left(2^{\prime}-\mathrm{OH}\right)$ dihedral during $\mathrm{QM} / \mathrm{MM}$ optimizations. Parameters setting for geometry restraints on the $\mathrm{U}_{\mathrm{L} 1}(\mathrm{C} 1$ '- $\mathrm{C} 2$ '-O 2 '-O2'H) dihedral includes $\mathrm{R}$, i.e., the target value of the dihedral restraint, varying in range of $60^{\circ}-190^{\circ}$ with a step length of $10^{\circ}$ along the scan, $r_{1}$ set to $R-10^{\circ}, r_{2}$ and $r_{3}$ equal to $R, r_{4}$ set to $R+10^{\circ}$, and $\mathrm{r}_{\mathrm{k} 2}$ and $\mathrm{r}_{\mathrm{k} 3}$ force constants set to $60 \mathrm{kcal} \cdot \mathrm{mol}^{-1} \cdot \mathrm{rad}^{2}$. Such a setting results into a two-sided parabolic-well potential restraint with well depth of $60 \mathrm{kcal} \cdot \mathrm{mol}^{-1} \cdot \mathrm{rad}^{2}$ in the range from $\mathrm{R}-10^{\circ}$ to $\mathrm{R}+10^{\circ}$ with linear extension outside of this range (for more information see the AMBER manual). 
S11. Details about the $\mathrm{U}_{\mathrm{L} 1}\left(\mathrm{C1}^{\prime}{ }^{\prime}-\mathrm{C}^{\prime}\right.$ '-O2'-O2'H) dihedral restraint applied during one set of REST2 folding simulations. We applied the one-sided flat-well potential restraint, so that the $\mathrm{C} 1$ '-C2'-O2'-O2'H dihedral was unrestrained below $115^{\circ}$, harmonic restraining potential with a force constant of $10 \mathrm{kcal} / \mathrm{mol} \cdot \mathrm{rad}^{2}$ was applied from $115^{\circ}$ to $135^{\circ}$, and linear extension of this potential was applied for dihedral values below above $135^{\circ}$. 


\section{S12. Supporting Tables}

Table S1. Overview of performed (and analyzed) unbiased MD simulations using various UUCG TL motifs.

\begin{tabular}{|c|c|c|c|c|c|}
\hline Motif & PDB ID & RNA ff & Modification $^{\mathrm{a}}$ & Simulations ${ }^{b}$ & $\begin{array}{c}\text { Length per } \\
\text { trajectory } \\
{[\mu \mathrm{s}]}\end{array}$ \\
\hline r(ggcacUUCGgugcc) & $2 \mathrm{KOC}$ & $\chi \mathrm{OL3CP}$ & gHBfix19 & $10,10^{\mathrm{c}}$ & $20 *, 0.5^{c}$ \\
\hline r(ggcacUUCGgugcc) & $2 \mathrm{KOC}$ & $\chi_{\mathrm{OL} 3 \mathrm{CP}}$ & $\begin{array}{c}\text { gHBfix19 + } \\
\text { NBfixoBPh }\end{array}$ & 3 & 0.1 \\
\hline r(acUUCGgu) & $2 \mathrm{KOC}$ & $\chi \mathrm{OL} 3 \mathrm{CP}$ & gHBfix19 & 2 & 0.1 \\
\hline r(gcUUCGgc) & $1 \mathrm{~F} 7 \mathrm{Y}$ & $\chi_{\mathrm{OL} 3 \mathrm{CP}}$ & gHBfix19 & 1 & 0.1 \\
\hline r(ggcacUUCGgugcc) & $2 \mathrm{KOC}$ & DESRES $^{\mathrm{d}}$ & - & 10 & $20 *$ \\
\hline
\end{tabular}

a inclusion of additional potential function tuning the stability of specific types of H-bonds (gHBfix), adjusting Lennard-Jones parameters with simultaneous modifications of the Lennard-Jones combining rules via nonbonded fix (NBfix), and possible other restrains (see main text for details).

${ }^{\mathrm{b}}$ number of independent simulations.

${ }^{\mathrm{c}}$ simulations using different water models and salt concentrations (see Table S12 for details).

${ }^{\mathrm{d}}$ RNA ff developed in the D.E. Shaw group (labelled in this manuscript as DESRES). ${ }^{26}$

* initial parts of simulations were taken from our previous works. ${ }^{18,27}$ Some of those were prolonged for this work.

Table S2. Overview of performed (and analyzed) enhanced sampling simulations of the UUCG 8 -mer motif.

\begin{tabular}{|c|c|c|c|c|}
\hline Motif & RNA $f f$ & Modification $^{\text {a }}$ & \# of replicas & $\begin{array}{l}\text { Length per } \\
\text { replica[ } \mu \mathrm{s}]\end{array}$ \\
\hline $\mathrm{r}$ (gcUUCGgc) & 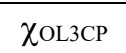 & gHBfix19 & 12 & $7 *$ \\
\hline $\mathrm{r}(\mathrm{gcUUUCGgc})$ & $\chi \mathrm{OL3CP}$ & $\operatorname{gHBfix} 19+\operatorname{gHBfix}\left({ }^{2-\mathrm{OH} \ldots \mathrm{N} / \mathrm{O}}\right) \mathrm{b}$ & 12 & $10 *$ \\
\hline $\mathrm{r}(\mathrm{gcUUCGgc})$ & $\chi \mathrm{OL3CP}$ & gHBfix $_{U N C G 19}{ }^{+0.5}$ & 12 & $20 *$ \\
\hline $\mathrm{r}(\mathrm{gcUUUCGgc})$ & $\chi \mathrm{OL} 3 \mathrm{CP}$ & gHBfixuNCG19 + NBfixoBPh & 16 & 20 \\
\hline $\mathrm{r}(\mathrm{gcUUUCGgc})$ & $\chi \mathrm{OL3CP}$ & $\begin{array}{c}\text { gHBfixuNCG } 19+\mathrm{NBfix}_{0 \mathrm{BPh}}+ \\
2-\mathrm{OH} \text { restraint }{ }^{\mathrm{d}}\end{array}$ & 16 & 20 \\
\hline
\end{tabular}

${ }^{a}$ inclusion of additional potential function tuning the stability of specific types of H-bonds (gHBfix), adjusting Lennard-Jones parameters with simultaneous modifications of the Lennard-Jones combining rules via nonbonded fix (NBfix), and possible other restraints (see main text for details).

${ }^{\mathrm{b}}$ see our original paper ${ }^{18}$ for the gHBfix notation.

${ }^{\mathrm{c}}$ see Table S16 for list of interactions modified by the gHBfixunCG19 potential.

d all replicas started from the folded (native-like) state.

* initial parts of simulations were taken from our previous works. ${ }^{18,27}$ Some of those were prolonged for this work. 
Table S3. Comparison of the $\mathrm{G}_{\mathrm{S}+1}\left(\mathrm{O}^{\prime}{ }^{\prime}\right) \ldots \mathrm{G}_{\mathrm{S}+1}\left(\mathrm{O}^{\prime}{ }^{\prime}\right)$, i.e., O...O distances (in $\AA$ ) between UUCG TLs after QM/MM and MM optimizations, and QM/MM $\rightarrow$ MM re-optimizations. ${ }^{\mathrm{a}}$

\begin{tabular}{|c|c|c|c|c|c|c|}
\hline & $\begin{array}{c}\text { Initial } \\
\text { value }\end{array}$ & $\mathrm{QM} / \mathrm{MM}$ & $\mathrm{MM}$ & $\begin{array}{c}\mathrm{QM} / \mathrm{MM} \\
\rightarrow \mathrm{MM} \\
\end{array}$ & $\Delta \mathrm{d}_{1}{ }^{\mathrm{b}}$ & $\Delta \mathrm{d}_{2}{ }^{\mathrm{c}}$ \\
\hline \multicolumn{7}{|c|}{ structure $\mathbf{6}$ - water equilibration structures $\mathbf{6 a - 6 e}$} \\
\hline $\mathbf{6 a}$ & 2.74 & 2.81 & 2.83 & 2.86 & 0.02 & 0.05 \\
\hline $6 \mathbf{b}$ & 2.74 & 2.73 & 2.79 & 2.78 & 0.06 & 0.05 \\
\hline 6c & 2.74 & 2.77 & 2.79 & 2.82 & 0.02 & 0.05 \\
\hline 6d & 2.74 & 2.77 & 2.84 & 2.80 & 0.07 & 0.03 \\
\hline $6 e$ & 2.74 & 2.78 & 2.83 & 2.86 & 0.05 & 0.08 \\
\hline average & & & & & 0.04 & 0.05 \\
\hline \multicolumn{7}{|c|}{ structure 7 - water equilibration structures $7 \mathbf{a}-7 \mathbf{e}$} \\
\hline $7 a$ & 2.70 & 2.66 & 2.72 & -- & 0.06 & -- \\
\hline $7 b$ & 2.70 & 2.69 & 2.77 & -- & 0.08 & -- \\
\hline $7 c$ & 2.70 & 2.70 & 2.76 & -- & 0.07 & -- \\
\hline $7 d$ & 2.70 & 2.75 & 2.79 & -- & 0.04 & -- \\
\hline $7 e$ & 2.70 & 2.75 & 2.84 & -- & 0.08 & -- \\
\hline average & & & & & 0.07 & \\
\hline \multicolumn{7}{|c|}{ structure 9 - water equilibration structures $9 \mathbf{a}-9 \mathbf{e}$} \\
\hline $9 a$ & 2.57 & 2.60 & 2.62 & 2.67 & 0.02 & 0.07 \\
\hline $9 b$ & 2.57 & 2.62 & 2.64 & 2.67 & 0.02 & 0.05 \\
\hline $9 \mathrm{c}$ & 2.57 & 2.55 & 2.62 & 2.60 & 0.07 & 0.05 \\
\hline 9d & 2.57 & 2.62 & 2.68 & 2.70 & 0.06 & 0.08 \\
\hline $9 e$ & 2.57 & 2.62 & 2.68 & 2.67 & 0.06 & 0.05 \\
\hline average $^{\mathrm{d}}$ & & & & & 0.05 & 0.06 \\
\hline
\end{tabular}

${ }^{a}$ Only structures with the native $\mathrm{GS}_{\mathrm{S}+1}$ phosphate, where $0 \mathrm{BPh}$ interaction is established, are listed. In the main text, only the results for structures $6 \mathbf{e}, 7 \mathbf{e}$ and $9 \mathrm{e}$ are shown. Note that the $\mathrm{QM} / \mathrm{MM} \rightarrow \mathrm{MM}$ re-optimizations were performed only for some structures as the results showed similar trend as the MM optimizations. ${ }^{\mathrm{b}} \Delta \mathrm{d}_{1}=\mathrm{MM}-\mathrm{QM} / \mathrm{MM},{ }^{\mathrm{c}} \Delta \mathrm{d}_{2}=(\mathrm{QM} / \mathrm{MM} \rightarrow \mathrm{MM})-\mathrm{QM} / \mathrm{MM}$, ${ }^{\mathrm{d}}$ structure 9b is excluded from the average calculation as flip of the $\mathrm{Gs}_{\mathrm{s}+1}$ phosphate occurred during the QM/MM optimization. 
Table S4. Comparison of the $\mathrm{G}_{\mathrm{S}+1}(\mathrm{C} 8 \mathrm{H} 8) \ldots \mathrm{G}_{\mathrm{S}+1}\left(\mathrm{O} 5^{\prime}\right)$, i.e., H...O distances (in $\AA$ ) between UUCG TLs after QM/MM and MM optimizations, and QM/MM $\rightarrow$ MM re-optimizations. ${ }^{a}$

\begin{tabular}{|c|c|c|c|c|c|c|}
\hline & $\begin{array}{l}\text { Initial } \\
\text { value }\end{array}$ & $\mathrm{QM} / \mathrm{MM}$ & $\mathrm{MM}$ & $\begin{array}{c}\mathrm{QM} / \mathrm{MM} \\
\rightarrow \mathrm{MM}\end{array}$ & $\Delta \mathrm{d}_{1}{ }^{\mathrm{b}}$ & $\Delta \mathrm{d}_{2}{ }^{\mathrm{c}}$ \\
\hline \multicolumn{7}{|c|}{ structure 6 - water equilibration structures $6 a-6 e$} \\
\hline $\mathbf{6 a}$ & 2.18 & 2.21 & 2.36 & 2.29 & 0.15 & 0.08 \\
\hline $6 \mathbf{b}$ & 2.18 & 2.18 & 2.31 & 2.32 & 0.13 & 0.14 \\
\hline 6c & 2.18 & 2.14 & 2.34 & 2.30 & 0.20 & 0.16 \\
\hline $6 d$ & 2.18 & 2.14 & 2.38 & 2.31 & 0.24 & 0.17 \\
\hline $6 e$ & 2.18 & 2.08 & 2.28 & 2.24 & 0.20 & 0.16 \\
\hline average & & & & & 0.18 & 0.14 \\
\hline \multicolumn{7}{|c|}{ structure 7 - water equilibration structures $7 \mathrm{a}-7 \mathrm{e}$} \\
\hline $7 \mathbf{a}$ & 2.39 & 2.39 & 2.52 & -- & 0.12 & - \\
\hline $7 b$ & 2.39 & 2.33 & 2.42 & -- & 0.08 & -- \\
\hline $7 c$ & 2.39 & 2.37 & 2.46 & -- & 0.09 & -- \\
\hline $7 d$ & 2.39 & 2.30 & 2.42 & -- & 0.13 & -- \\
\hline $7 e$ & 2.39 & 2.39 & 2.48 & -- & 0.09 & -- \\
\hline average & & & & & 0.10 & \\
\hline \multicolumn{7}{|c|}{ structure 9 - water equilibration structures $9 \mathrm{a}-9 \mathrm{e}$} \\
\hline $9 \mathbf{a}$ & 2.15 & 2.19 & 2.27 & 2.24 & 0.08 & 0.05 \\
\hline $9 b$ & 2.15 & 2.92 & 2.24 & 2.92 & -0.68 & 0.00 \\
\hline $9 c$ & 2.15 & 2.11 & 2.28 & 2.25 & 0.17 & 0.14 \\
\hline 9d & 2.15 & 2.30 & 2.35 & 2.30 & 0.05 & 0.00 \\
\hline $9 e$ & 2.15 & 2.21 & 2.30 & 2.30 & 0.09 & 0.09 \\
\hline average $^{\mathrm{d}}$ & & & & & 0.10 & 0.07 \\
\hline
\end{tabular}

${ }^{a}$ Only structures with the native $\mathrm{GS}_{\mathrm{S}+1}$ phosphate, where $0 \mathrm{BPh}$ interaction is established, are listed. In the main text, only the results for structures $6 \mathbf{e}, 7 \mathbf{e}$ and $9 \mathrm{e}$ are shown. Note that the $\mathrm{QM} / \mathrm{MM} \rightarrow \mathrm{MM}$ re-optimizations were performed only for some structures as the results showed similar trend as the MM optimizations. ${ }^{\mathrm{b}} \Delta \mathrm{d}_{1}=\mathrm{MM}-\mathrm{QM} / \mathrm{MM},{ }^{\mathrm{c}} \Delta \mathrm{d}_{2}=(\mathrm{QM} / \mathrm{MM} \rightarrow \mathrm{MM})-\mathrm{QM} / \mathrm{MM}$, ${ }^{\mathrm{d}}$ structure 9b is excluded from the average calculation as flip of the $\mathrm{Gs}_{\mathrm{s}+1}$ phosphate occurred during the QM/MM optimization. 
Table S5. Comparison of the $\mathrm{G}_{\mathrm{S}+1}(\mathrm{C} 8 \mathrm{H} 8) \ldots \mathrm{G}_{\mathrm{S}+1}\left(\mathrm{O}^{\prime}{ }^{\prime}\right)$, i.e., $\mathrm{H} \ldots \mathrm{O}$ and $\mathrm{G}_{\mathrm{S}+1}\left(\mathrm{O}^{\prime}\right)$ - $\mathrm{G}_{\mathrm{S}+1}\left(\mathrm{O}^{\prime}\right)$, i.e., $\mathrm{O}$ - O distances (in $\AA$ ) between the two dinucleoside monophosphate models with the native $\mathrm{G}_{\mathrm{S}+1}$ phosphate (planar-native and tilted-native) optimized with or without geometrical restraints (restrained and free optimizations, respectively) by QM/COSMO or MM/GB (see Section S4 for computational details).

\begin{tabular}{|c|c|c|c|c|c|c|}
\hline free optimizatic & start & $\mathrm{QM}$ & $\Delta \mathrm{d}_{\mathrm{QM}}$ & $\mathrm{MM}$ & $\Delta \mathrm{d}_{\mathrm{MM}}$ & $\Delta \mathrm{d}_{\mathrm{MM}-\mathrm{QM}}$ \\
\hline \multicolumn{7}{|l|}{ planar-native } \\
\hline $\begin{array}{l}\mathrm{G}_{\mathrm{S}+1}\left(\mathrm{H} 8 / \mathrm{O}^{\prime}\right) \\
\mathrm{G}_{\mathrm{S}+1}\left(\mathrm{O} 4^{\prime} / \mathrm{O}^{\prime}\right) \\
\end{array}$ & $\begin{array}{l}2.37 \\
2.76 \\
\end{array}$ & $\begin{array}{l}2.28 \\
2.80 \\
\end{array}$ & $\begin{array}{r}-0.09 \\
0.04 \\
\end{array}$ & $\begin{array}{l}2.56 \\
2.90\end{array}$ & $\begin{array}{l}0.19 \\
0.14\end{array}$ & $\begin{array}{l}0.28 \\
0.10 \\
\end{array}$ \\
\hline \multicolumn{7}{|l|}{ tilted-native } \\
\hline $\begin{array}{l}\mathrm{G}_{\mathrm{S}+1}\left(\mathrm{H} 8 / \mathrm{O}^{\prime}\right) \\
\mathrm{G}_{\mathrm{S}+1}\left(\mathrm{O} 4{ }^{\prime} / \mathrm{O} 5\right. \\
\end{array}$ & $\begin{array}{l}2.18 \\
2.74\end{array}$ & $\begin{array}{l}2.29 \\
2.80 \\
\end{array}$ & $\begin{array}{l}0.11 \\
0.06\end{array}$ & $\begin{array}{l}2.56 \\
2.90\end{array}$ & $\begin{array}{l}0.38 \\
0.16\end{array}$ & $\begin{array}{l}0.27 \\
0.10 \\
\end{array}$ \\
\hline
\end{tabular}

restrained optimizations

\begin{tabular}{cccccc} 
start & $\mathrm{QM}$ & $\Delta \mathrm{d}_{\mathrm{QM}}$ & $\mathrm{MM}$ & $\Delta \mathrm{d}_{\mathrm{MM}}$ & $\Delta \mathrm{d}_{\mathrm{MM}} \mathrm{QM}$ \\
\hline
\end{tabular}

planar-native

\begin{tabular}{lllllll}
\hline Gs $+1\left(\mathrm{H} 8 / \mathrm{O}^{\prime}\right)$ & 2.37 & 2.23 & -0.14 & 2.50 & 0.13 & 0.27 \\
$\mathrm{Gs}^{\prime}\left(\mathrm{O} 4^{\prime} / \mathrm{O} 5^{\prime}\right)$ & 2.76 & 2.71 & -0.05 & 2.87 & 0.11 & 0.16 \\
\hline
\end{tabular}

tilted-native

\begin{tabular}{lllllll}
\hline Gs $+1\left(\mathrm{H} 8 / \mathrm{O}^{\prime}\right)$ & 2.18 & 2.22 & 0.04 & 2.44 & 0.26 & 0.22 \\
$\mathrm{Gs}^{\prime}\left(\mathrm{O} 4^{\prime} / \mathrm{O} 5^{\prime}\right)$ & 2.74 & 2.74 & 0.00 & 2.80 & 0.06 & 0.06 \\
\hline
\end{tabular}


Table S6. Relative QM and MM energies (in $\mathrm{kcal} / \mathrm{mol}$ ) of the four dinucleoside monophosphate models (planar-native, tilted-native, planar-flipped and tilted-flipped) optimized with geometrical restraints on dihedrals using QM (PBEh-3c) or MM (ff99bsc0 $\chi_{\mathrm{OL} 3 \mathrm{CP}}$ ) method with COSMO and GB implicit solvent, respectively. ${ }^{\mathrm{a}}$

\begin{tabular}{|c|c|c|c|c|}
\hline \multicolumn{3}{|c|}{ QM optimized } & \multicolumn{2}{|c|}{ MM optimized } \\
\hline $\mathrm{G}_{\mathrm{L} 4-\mathrm{G}_{\mathrm{S}+1}}$ & $\Delta \mathrm{E}_{\text {conf,QM }}$ & $\Delta \mathrm{E}_{\text {conf, } \mathrm{MM}}$ & $\Delta \mathrm{E}_{\text {conf,QM }}$ & $\Delta \mathrm{E}_{\text {conf,MM }}$ \\
\hline \multicolumn{5}{|c|}{ implicit solvent single point calculations } \\
\hline planar-native & 0.78 & 0.00 & 1.57 & 0.00 \\
\hline planar-flipped & 3.90 & 8.00 & 5.71 & 7.71 \\
\hline tilted-native & 0.00 & 3.26 & 0.00 & 3.64 \\
\hline tilted-flipped & 2.17 & 3.53 & 0.61 & 3.98 \\
\hline \multicolumn{5}{|c|}{ gas phase single point calculations } \\
\hline planar-native & 5.40 & 2.53 & 5.88 & 1.84 \\
\hline planar-flipped & 5.81 & 9.68 & 9.95 & 10.58 \\
\hline tilted-native & 0.00 & 0.00 & 0.00 & 0.00 \\
\hline tilted-flipped & 10.90 & 10.04 & 9.33 & 11.73 \\
\hline
\end{tabular}

${ }^{a}$ See Section S4 for computational details and dihedral restraints. The most stable structure in each column has energy $0 \mathrm{kcal} / \mathrm{mol}$. Single point energy calculations are performed either with implicit solvent or in gas phase. 
Table S7. Comparison of the O...N and H...N distances, i.e., donor-acceptor and hydrogenacceptor distances (in $\AA$, separated by “"”) of the $\mathrm{U}_{\mathrm{L} 2}\left(2^{\prime}-\mathrm{OH}\right) \ldots \mathrm{G}_{\mathrm{L} 4}(\mathrm{~N} 7) \mathrm{H}-$ bond in UUCG TLs after $\mathrm{QM} / \mathrm{MM}$ and $\mathrm{MM}$ optimizations, and $\mathrm{QM} / \mathrm{MM} \rightarrow \mathrm{MM}^{\mathrm{Ne}-\text { optimizations. }}{ }^{\mathrm{a}}$

\begin{tabular}{|c|c|c|c|c|c|c|}
\hline structure & initial value & QM/MM & MM & $\begin{array}{c}\mathrm{QM} / \mathrm{MM} \\
\rightarrow \mathrm{MM} \\
\end{array}$ & $\Delta \mathrm{d}_{1}{ }^{\mathrm{b}}$ & $\Delta \mathrm{d}_{2}{ }^{\mathrm{c}}$ \\
\hline 1 & $2.89 / 2.06$ & $2.86 / 1.92$ & $2.80 / 1.92$ & $2.82 / 1.93$ & $-0.06 /-0.01$ & $-0.04 / 0.01$ \\
\hline 2 & $2.73 / 2.14$ & $2.72 / 1.76$ & $2.78 / 1.97$ & $2.73 / 1.86$ & $0.06 / 0.21$ & $0.01 / 0.10$ \\
\hline 4 & $2.93 / 2.12$ & $2.76 / 1.84$ & $2.82 / 2.11$ & $2.79 / 2.00$ & $0.06 / 0.27$ & $0.03 / 0.16$ \\
\hline \multicolumn{7}{|c|}{ structure 5 - water equilibration structures $5 \mathrm{a}-5 \mathrm{e}$} \\
\hline $5 \mathbf{a}$ & $2.75 / 1.83$ & $2.82 / 1.87$ & $2.89 / 2.03$ & $2.80 / 1.86$ & $0.07 / 0.15$ & $-0.02 /-0.01$ \\
\hline $5 \mathbf{b}$ & $2.75 / 1.83$ & $2.79 / 1.83$ & $2.82 / 1.90$ & $2.76 / 1.83$ & $0.03 / 0.07$ & $-0.03 / 0.00$ \\
\hline $5 \mathbf{c}$ & $2.75 / 1.83$ & $2.76 / 1.78$ & $2.88 / 1.94$ & $2.74 / 1.78$ & $0.12 / 0.16$ & $-0.02 / 0.00$ \\
\hline 5d & $2.75 / 1.83$ & $2.80 / 1.82$ & $2.77 / 1.82$ & $2.75 / 1.81$ & $-0.03 /-0.01$ & $-0.05 /-0.01$ \\
\hline $5 e$ & $2.75 / 1.83$ & $2.88 / 1.95$ & $2.89 / 1.96$ & $2.83 / 1.90$ & $0.02 / 0.01$ & $-0.05 /-0.05$ \\
\hline average & & & & & $0.04 / 0.08$ & $-0.03 /-0.01$ \\
\hline \multicolumn{7}{|c|}{ structure $\mathbf{6}$ - water equilibration structures $5 \mathrm{a}-5 \mathrm{e}$} \\
\hline $\mathbf{6 a}$ & $2.71 / 1.80$ & $2.71 / 1.73$ & $2.72 / 1.75$ & $2.70 / 1.72$ & $0.01 / 0.02$ & $-0.01 /-0.01$ \\
\hline 6b & $2.71 / 1.80$ & $2.80 / 1.85$ & $2.78 / 1.93$ & $2.76 / 1.89$ & $-0.02 / 0.08$ & $-0.04 / 0.04$ \\
\hline 6c & $2.71 / 1.80$ & $2.68 / 1.72$ & $2.84 / 2.07$ & $2.68 / 1.78$ & $0.17 / 0.35$ & $0.00 / 0.06$ \\
\hline 6d & $2.71 / 1.80$ & $2.77 / 1.82$ & $2.86 / 2.11$ & $2.74 / 1.85$ & $0.09 / 0.29$ & $-0.03 / 0.03$ \\
\hline $6 e$ & $2.71 / 1.80$ & $2.98 / 2.03$ & $2.95 / 2.07$ & $2.91 / 1.98$ & $-0.03 / 0.04$ & $-0.07 /-0.05$ \\
\hline average & & & & & $0.04 / 0.16$ & $-0.03 / 0.01$ \\
\hline \multicolumn{7}{|c|}{ structure 9 - water equilibration geometries a-e } \\
\hline 9a & $2.72 / 1.88$ & $2.72 / 1.75$ & $2.74 / 1.86$ & $2.69 / 1.76$ & $0.03 / 0.11$ & $-0.03 / 0.01$ \\
\hline $9 b$ & $2.72 / 1.88$ & $2.70 / 1.74$ & $2.74 / 1.89$ & $2.69 / 1.79$ & $0.04 / 0.15$ & $-0.01 / 0.05$ \\
\hline 9c & $2.72 / 1.88$ & $2.84 / 1.86$ & $2.74 / 1.89$ & $2.81 / 1.84$ & $-0.10 / 0.03$ & $-0.03 /-0.02$ \\
\hline 9d & $2.72 / 1.88$ & $2.83 / 1.88$ & $2.80 / 1.91$ & $2.80 / 1.91$ & $-0.03 / 0.04$ & $-0.03 / 0.03$ \\
\hline $9 \mathrm{e}$ & $2.72 / 1.88$ & $2.82 / 1.86$ & $2.80 / 1.96$ & $2.75 / 1.85$ & $-0.03 / 0.10$ & $-0.07 /-0.01$ \\
\hline average & & & & & $-0.02 / 0.09$ & $-0.03 / 0.01$ \\
\hline
\end{tabular}

${ }^{a}$ Each column contains two values separated by a slash, the first number represents $\mathrm{O} \ldots \mathrm{N}$ donor-acceptor distance and the second number represents $\mathrm{H} . . . \mathrm{N}$ hydrogen-acceptor distance. Note that structure $\mathbf{3}$ is not included in this analysis because $\mathrm{U}_{\mathrm{L} 2}\left(2^{\prime}-\mathrm{OH}\right)$ forms an alternative H-bond with $\mathrm{G}_{\mathrm{L} 4}(\mathrm{O} 6)$ instead of $\mathrm{G}_{\mathrm{L} 4}(\mathrm{~N} 7)$ atom. Structures 7 and 8 are not included in this analysis because spurious state of the $\mathrm{U}_{\mathrm{L} 1}\left(2^{\prime}-\mathrm{OH}\right)$ group is present in these structures, which may possibly influence position of the GL4 nucleobase and subsequently the $\mathrm{U}_{\mathrm{L} 2}\left(2^{\prime}-\mathrm{OH}\right) \ldots \mathrm{G}_{\mathrm{L} 4}(\mathrm{~N} 7)$ H-bond. ${ }^{\mathrm{b}} \Delta \mathrm{d}_{1}=\mathrm{MM}-\mathrm{QM} / \mathrm{MM},{ }^{\mathrm{c}} \Delta \mathrm{d}_{2}=(\mathrm{QM} / \mathrm{MM} \rightarrow \mathrm{MM})-\mathrm{QM} / \mathrm{MM}$. 
Table S8. Comparison of the $\mathrm{O}-\mathrm{H} \ldots \mathrm{N}$ angle of the $\mathrm{U}_{\mathrm{L} 2}\left(2^{\prime}-\mathrm{OH}\right) \ldots \mathrm{G}_{\mathrm{L} 4}(\mathrm{~N} 7) \mathrm{H}$-bond (in ${ }^{\circ}$ ) in UUCG TLs after QM/MM and MM optimizations, and QM/MM $\rightarrow$ MM re-optimizations. ${ }^{a}$

\begin{tabular}{|c|c|c|c|c|c|c|}
\hline Structure & $\begin{array}{l}\text { initial } \\
\text { value }\end{array}$ & $\mathrm{QM} / \mathrm{MM}$ & $\mathrm{MM}$ & $\begin{array}{c}\mathrm{QM} / \mathrm{MM} \\
\rightarrow \mathrm{MM}\end{array}$ & $\Delta \mathrm{a}_{1}{ }^{\mathrm{b}}$ & $\Delta \mathrm{a}_{2}{ }^{\mathrm{c}}$ \\
\hline 1 & 143.4 & 159.5 & 148.6 & 149.7 & -10.9 & -9.8 \\
\hline 2 & 118.1 & 163.3 & 138.9 & 146.5 & -24.4 & -16.7 \\
\hline 4 & 140.8 & 155.2 & 128.2 & 135.9 & -27.0 & -19.3 \\
\hline \multicolumn{7}{|c|}{ structure $\mathbf{5}$ - water equilibration structures $\mathbf{5 a - 5 e}$} \\
\hline $5 \mathbf{a}$ & 161.7 & 161.6 & 146.8 & 159.3 & -14.8 & -2.3 \\
\hline $5 \mathbf{b}$ & 161.7 & 166.3 & 157.5 & 157.9 & -8.8 & -8.3 \\
\hline $5 c$ & 161.7 & 168.2 & 160.2 & 163.9 & -8.0 & -4.3 \\
\hline 5d & 161.7 & 171.0 & 164.2 & 159.0 & -6.7 & -11.9 \\
\hline $5 e$ & 161.7 & 158.6 & 159.8 & 158.5 & 1.2 & -0.1 \\
\hline Average & & & & & -7.4 & -5.4 \\
\hline \multicolumn{7}{|c|}{ structure $\mathbf{6}$ - water equilibration structures $\mathbf{6 a - 6 e}$} \\
\hline 6a & 157.0 & 172.4 & 171.8 & 172.5 & -0.6 & 0.1 \\
\hline $\mathbf{6 b}$ & 157.0 & 162.2 & 143.6 & 145.3 & -18.6 & -16.9 \\
\hline 6c & 157.0 & 162.0 & 135.8 & 150.7 & -26.2 & -11.3 \\
\hline 6d & 157.0 & 160.7 & 132.6 & 148.1 & -28.1 & -12.6 \\
\hline $6 e$ & 157.0 & 162.5 & 150.0 & 158.1 & -12.5 & -4.4 \\
\hline Average & & & & & -17.2 & -9.0 \\
\hline \multicolumn{7}{|c|}{ structure 9 - water equilibration structures $9 \mathbf{a}-9 \mathrm{e}$} \\
\hline 9a & 143.5 & 168.2 & 149.3 & 157.1 & -14.8 & -7.0 \\
\hline 9b & 143.5 & 176.2 & 144.3 & 151.2 & -19.2 & -12.3 \\
\hline $9 c$ & 143.5 & 163.6 & 144.8 & 170.0 & -30.1 & -4.9 \\
\hline 9d & 143.5 & 158.1 & 149.7 & 149.6 & -14.3 & -14.4 \\
\hline $9 \mathrm{e}$ & 143.5 & 161.8 & 142.6 & 151.5 & -26.5 & -17.6 \\
\hline Average & & & & & -21.0 & -11.2 \\
\hline
\end{tabular}

${ }^{a}$ Note that structure 3 is not included in this analysis because UL2(2'-OH) forms an alternative H-bond with GL4(O6) instead of GL4(N7) atom. Structures $\mathbf{7}$ and $\mathbf{8}$ are not included in this analysis because spurious state of the UL1(2'$\mathrm{OH})$ group is present in these structures, which may possibly influence position of the GL4 nucleobase and subsequently the $\mathrm{UL}_{\mathrm{L} 2}\left(2^{\prime}-\mathrm{OH}\right) \ldots \mathrm{G} \mathrm{L} 4(\mathrm{~N} 7) \mathrm{H}$-bond. ${ }^{\mathrm{b}} \Delta \mathrm{a}_{1}=\mathrm{MM}-\mathrm{QM} / \mathrm{MM},{ }^{\mathrm{c}} \Delta \mathrm{a}_{2}=(\mathrm{QM} / \mathrm{MM} \rightarrow \mathrm{MM})-\mathrm{QM} / \mathrm{MM}$. Note that both comparisons predict visible underestimation of the angle at the MM level of theory. Use of the $\mathrm{QM} / \mathrm{MM} \rightarrow \mathrm{MM}$ optimized structures leads to a smaller difference than use of the MM optimized structures, for reasons that are in more detail commented on in ref. ${ }^{28}$.

Table S9. Optimized values of $\mathrm{U}_{\mathrm{L} 2}$ ribose $\mathrm{C} 2$ ' $-\mathrm{O} 2$ '- $\mathrm{O} 2$ ' $\mathrm{H}$ angle and $\mathrm{C} 1$ '-C2'-O2'-O2'H dihedral (in $\left.{ }^{\circ}\right)$. Starting ribose model for QM (PBEh-3c) and $\mathrm{MM}\left(f f 99 \mathrm{bsc} 0_{\mathrm{CP}}\right)$ geometry optimizations was taken from structure 9.

\begin{tabular}{l|ll}
\hline & angle & dihedral \\
& C2'-O2'-O2'H & C1'-C2'-O2'-O2'H \\
\hline start (structure 9) & 110.4 & 163.2 \\
PBEh-3c & 109.3 & 189.8 \\
ff99bsc0 & 106.5 & 261.3 \\
\hline
\end{tabular}


Table S10. Comparison of the $\mathrm{U}_{\mathrm{L} 2}$ ribose $\mathrm{C1}^{\prime}-\mathrm{C} 2^{\prime}-\mathrm{O} 2^{\prime}-\mathrm{O} 2^{\prime} \mathrm{H}$ dihedral (in ${ }^{\circ}$ ) of the $\mathrm{QM} / \mathrm{MM}-$ and MM-optimized UUCG TLs. ${ }^{\mathrm{a}}$

\begin{tabular}{|c|c|c|c|c|c|c|}
\hline structure & Initial value & QM/MM & MM & $\begin{array}{c}\mathrm{QM} / \mathrm{MM} \rightarrow \\
\mathrm{MM}\end{array}$ & $\Delta \mathrm{a}_{1}^{\mathrm{b}}$ & $\Delta \mathrm{a}_{2} \mathrm{c}$ \\
\hline 1 & 210.9 & 180.7 & 186.6 & 182.7 & 5.9 & 2.0 \\
\hline 2 & 181.0 & 171.4 & 187.9 & 181.5 & 16.5 & 10.1 \\
\hline 4 & 203.3 & 183.2 & 192.9 & 193.2 & 9.7 & 10.0 \\
\hline \multicolumn{7}{|c|}{ structure $\mathbf{5}$ - water equilibration structures $\mathbf{5 a - 5 e}$} \\
\hline $5 \mathbf{5 a}$ & 158.1 & 166.5 & 167.3 & 171.7 & 0.8 & 5.2 \\
\hline $5 \mathbf{b}$ & 158.1 & 168.7 & 171.1 & 175.3 & 2.4 & 6.6 \\
\hline $5 \mathbf{c}$ & 158.1 & 160.0 & 178.2 & 170.3 & 18.2 & 10.3 \\
\hline 5d & 158.1 & 166.9 & 174.0 & 175.7 & 7.1 & 8.8 \\
\hline $5 e$ & 158.1 & 143.9 & 150.7 & 146.9 & 6.8 & 3.0 \\
\hline average & & & & & 7.1 & 6.8 \\
\hline \multicolumn{7}{|c|}{ structure $\mathbf{6}$ - water equilibration structures $\mathbf{6 a - 6 e}$} \\
\hline 6a & 193.8 & 167.8 & 171.4 & 173.8 & 3.6 & 6.0 \\
\hline 6b & 193.8 & 193.4 & 210.0 & 202.6 & 16.6 & 9.2 \\
\hline 6c & 193.8 & 175.8 & 170.8 & 184.1 & -5.0 & 8.3 \\
\hline 6d & 193.8 & 189.9 & 189.0 & 194.0 & -0.9 & 4.1 \\
\hline 6e & 193.8 & 171.6 & 183.0 & 179.6 & 11.4 & 8.0 \\
\hline average & & & & & 5.1 & 7.1 \\
\hline \multicolumn{7}{|c|}{ structure 9 - water equilibration structures $9 \mathbf{a}-9 \mathbf{e}$} \\
\hline $9 \mathbf{a}$ & 175.8 & 168.2 & 164.2 & 170.0 & -4.0 & 1.8 \\
\hline 9b & 175.8 & 176.2 & 185.1 & 182.6 & 8.9 & 6.4 \\
\hline $9 c$ & 175.8 & 163.6 & 206.8 & 173.1 & 43.2 & 9.5 \\
\hline 9d & 175.8 & 158.1 & 169.8 & 168.3 & 11.7 & 10.2 \\
\hline $9 e$ & 175.8 & 161.8 & 181.6 & 173.9 & 19.8 & 12.1 \\
\hline average & & & & & 15.9 & 8.0 \\
\hline
\end{tabular}

${ }^{a}$ Note that structure 3 is not included in the table because $\mathrm{U}_{\mathrm{L} 2}\left(2^{\prime}-\mathrm{OH}\right)$ forms an alternative H-bond with GL4(O 6$)$ instead of $\mathrm{G}_{\mathrm{L} 4}(\mathrm{~N} 7)$ atom. Structures $\mathbf{7}$ and $\mathbf{8}$ are not included in the table because spurious state of the $\mathrm{U}_{\mathrm{L} 1}\left(2^{\prime}-\mathrm{OH}\right)$ group is present in these structures, which may possibly influence position of the GL4 nucleobase and subsequently the $\mathrm{U}_{\mathrm{L} 2}\left(2^{\prime}-\mathrm{OH}\right) \ldots \mathrm{G}_{\mathrm{L} 4}(\mathrm{~N} 7) \mathrm{H}$-bond. ${ }^{\mathrm{b}} \Delta \mathrm{a}_{1}=\mathrm{MM}-\mathrm{QM} / \mathrm{MM},{ }^{\mathrm{c}} \Delta \mathrm{a}_{2}=(\mathrm{QM} / \mathrm{MM} \rightarrow \mathrm{MM})-\mathrm{QM} / \mathrm{MM}$ 
Table S11. Directionality of the HB1 and HB2 H-bonds in the RNA kink-turn 7, defined by the $\mathrm{G}\left(\mathrm{O} 2^{\prime}\right)-\mathrm{G}\left(\mathrm{O} 2^{\prime} \mathrm{H}\right)-\mathrm{A}(\mathrm{N} 1)$ angle (in $\left.{ }^{\circ}\right){ }^{\mathrm{a}}$

\begin{tabular}{|c|c|c|c|c|c|}
\hline structure & MD average & initial value & $\mathrm{QM} / \mathrm{MM}$ & MM & $\Delta \mathrm{d}_{\mathrm{MM}-\mathrm{QM} / \mathrm{MM}}$ \\
\hline & \multicolumn{5}{|c|}{ HB1 } \\
\hline $1 \mathrm{a}$ & \multirow{7}{*}{161.2} & 164.5 & 172.4 & 178.1 & 5.7 \\
\hline $2 \mathbf{a}$ & & 175.8 & 169.7 & 171.5 & 1.8 \\
\hline $2 \mathrm{~b}$ & & 175.8 & 169.0 & 171.8 & 2.8 \\
\hline $2 c$ & & 175.8 & 166.8 & 171.2 & 4.4 \\
\hline $3 \mathbf{a}$ & & 161.7 & 167.5 & 166.2 & -1.3 \\
\hline $3 b$ & & 161.7 & 168.7 & 168.8 & 0.1 \\
\hline \multirow[t]{2}{*}{$3 c$} & & 161.7 & 168.8 & 164.2 & -4.5 \\
\hline & \multicolumn{5}{|c|}{ HB2 } \\
\hline $1 \mathbf{a}$ & \multirow{7}{*}{163.8} & 153.1 & 167.6 & 159.5 & -8.2 \\
\hline $2 \mathbf{a}$ & & 172.7 & 172.5 & 171.2 & -1.2 \\
\hline $2 \mathbf{b}$ & & 172.7 & 171.0 & 177.9 & 6.9 \\
\hline $2 c$ & & 172.7 & 172.3 & 174.9 & 2.6 \\
\hline $3 \mathbf{a}$ & & 162.6 & 172.3 & 168.5 & -3.7 \\
\hline $\mathbf{3 b}$ & & 162.6 & 170.9 & 172.3 & 1.5 \\
\hline $3 c$ & & 162.6 & 173.9 & 176.6 & 2.6 \\
\hline
\end{tabular}

${ }^{a}$ Average values in the MD simulations, the values in structures used as the initial geometries for the QM/MM and MM optimizations, and the resulting values of respective optimizations are presented. Structures $\mathbf{1}$, 2, and $\mathbf{3}$ represent three different RNA geometries taken from MD simulations and notations $\mathbf{a}, \mathbf{b}$ and $\mathbf{c}$ represent three different water distributions introduced around the RNA for each structure. $\Delta \mathrm{d}_{\mathrm{MM}} \mathrm{-QM} / \mathrm{Mm}$ column shows the difference between MM-optimized and QM/MM-optimized geometry and is calculated as MM - QM/MM. 
Table S12. Population (in \%) of the alternative $\mathrm{U}_{\mathrm{L} 1}\left(2^{\prime}-\mathrm{OH}\right) \ldots \mathrm{U}_{\mathrm{L} 1}\left(\mathrm{O} 5^{\prime}\right)$ H-bond, i.e. $\mathrm{U}_{\mathrm{L} 1}\left(2^{\prime}-\mathrm{OH}\right)$ base-phosphate flipping, in MD simulations of the r(ggcacUUCGgugcc) 14-mer using different water models (OPC, SPC/E and TIP3P) and salt concentration (0.15 M, 1.0 M and net-neutral).

\begin{tabular}{c|rrr}
\hline Gs+1 phosphate & $0.15 \mathrm{M} \mathrm{KCl}$ & $0.15 \mathrm{M} \mathrm{KCl} / \mathrm{CP}^{\mathrm{a}}$ & $1.0 \mathrm{M} \mathrm{KCl} / \mathrm{CP}$ \\
\hline Native & 89.4 & 85.2 & 79.6 \\
flipped & 10.6 & 14.8 & 20.4 \\
\hline Gs+1 phosphate & $0.15 \mathrm{M} \mathrm{KCl}$ & $0.15 \mathrm{M} \mathrm{KCl} / \mathrm{CP}$ & $1.0 \mathrm{M} \mathrm{KCl}$ \\
\hline Native & 78.6 & 75.5 & 72.2 \\
flipped & 21.4 & 24.5 & 27.8 \\
\hline Gs+1 phosphate & $0.15 \mathrm{M} \mathrm{KCl}$ & Net-neutral & $1.0 \mathrm{M} \mathrm{KCl}$ \\
\hline Native & 87.2 & 90.9 & 80.7 \\
flipped & 12.8 & 9.1 & 19.3 \\
\hline
\end{tabular}

${ }^{\mathrm{a}} \mathrm{CP}=$ Case phosphates paramaters 
Table S13. Ribose-base stacking between the $\mathrm{C}_{\mathrm{L} 3}$ ribose and the $\mathrm{G}_{\mathrm{L} 4}$ nucleobase represented by a distance between the $\mathrm{C}_{\mathrm{L} 3}\left(\mathrm{O}^{\prime}\right)$ oxygen atom and the $\mathrm{G}_{\mathrm{L} 4}$ nucleobase plane (in $\AA$ ) in the QM/MM- and MM-optimized UUCG TLs and a comparison between these methods. ${ }^{\mathrm{a}}$

\begin{tabular}{lrrrrrr}
\hline structure & $\begin{array}{l}\text { initial } \\
\text { value }\end{array}$ & \multicolumn{1}{c}{$\mathrm{QM} / \mathrm{MM}$} & $\mathrm{MM}$ & $\Delta \mathrm{d}_{\mathrm{QM} / \mathrm{MM}^{\mathrm{b}}}$ & $\Delta \mathrm{d}_{\mathrm{MM}^{\mathrm{c}}}$ & $\Delta \mathrm{d}_{1}{ }^{\mathrm{d}}$ \\
\hline $\mathbf{1}$ & 3.19 & 2.80 & 2.93 & -0.39 & -0.26 & 0.13 \\
$\mathbf{2}$ & 2.92 & 2.82 & 2.83 & -0.10 & -0.09 & 0.02 \\
$\mathbf{3}$ & 2.76 & 2.82 & 2.84 & 0.06 & 0.08 & 0.02 \\
$\mathbf{4}$ & 2.89 & 2.82 & 2.78 & -0.08 & -0.12 & -0.04 \\
\hline
\end{tabular}

structure $\mathbf{5}$ - water equilibration structures $\mathbf{5 a - 5 e}$

\begin{tabular}{llllrrr}
\hline $\mathbf{5 a}$ & 2.81 & 2.70 & 2.81 & -0.11 & 0.00 & 0.11 \\
$\mathbf{5 b}$ & 2.81 & 2.86 & 2.79 & 0.05 & -0.02 & -0.07 \\
$\mathbf{5 c}$ & 2.81 & 2.66 & 2.75 & -0.15 & -0.06 & 0.09 \\
$\mathbf{5 d}$ & 2.81 & 2.76 & 2.80 & -0.05 & -0.01 & 0.05 \\
$\mathbf{5 e}$ & 2.81 & 2.71 & 2.78 & -0.10 & -0.03 & 0.07 \\
\hline average & & & & & & 0.05 \\
\hline
\end{tabular}

structure 6 - water equilibration structures 6a-6e

\begin{tabular}{lrlllrr}
\hline $\mathbf{6 a}$ & 2.95 & 2.84 & 2.86 & -0.12 & -0.10 & 0.02 \\
$\mathbf{6 b}$ & 2.95 & 2.92 & 2.88 & -0.03 & -0.07 & -0.03 \\
$\mathbf{6 c}$ & 2.95 & 2.81 & 2.86 & -0.14 & -0.09 & 0.05 \\
$\mathbf{6 d}$ & 2.95 & 2.80 & 2.87 & -0.15 & -0.08 & 0.07 \\
$\mathbf{6 e}$ & 2.95 & 2.90 & 2.91 & -0.05 & -0.04 & 0.01 \\
\hline average & & & & & & 0.02 \\
\hline
\end{tabular}

structure $\mathbf{8}$ - water equilibration structures 8a-8e

\begin{tabular}{lrrrrrr}
\hline $\mathbf{8 a}$ & 3.03 & 2.86 & 2.92 & -0.18 & -0.12 & 0.06 \\
$\mathbf{8 b}$ & 3.03 & 2.84 & 2.85 & -0.19 & -0.18 & 0.01 \\
$\mathbf{8 c}$ & 3.03 & 2.84 & 2.87 & -0.19 & -0.17 & 0.03 \\
$\mathbf{8 d}$ & 3.03 & 2.99 & 3.01 & -0.05 & -0.02 & 0.03 \\
$\mathbf{8 e}$ & 3.03 & 2.98 & 2.93 & -0.06 & -0.10 & -0.05 \\
\hline average & & & & & & 0.02 \\
\hline
\end{tabular}

structure 9 - water equilibration structures 9a-9e

\begin{tabular}{lrrrrrr}
\hline 9a & 2.87 & 2.82 & 2.92 & -0.05 & 0.05 & 0.09 \\
$\mathbf{9 b}$ & 2.87 & 2.89 & 2.95 & 0.02 & 0.08 & 0.06 \\
$\mathbf{9 c}$ & 2.87 & 2.92 & 2.89 & 0.05 & 0.02 & -0.03 \\
$\mathbf{9 d}$ & 2.87 & 2.97 & 2.95 & 0.10 & 0.08 & -0.02 \\
9e & 2.87 & 2.84 & 2.84 & -0.04 & -0.03 & 0.01 \\
\hline average & & & & & & 0.02 \\
\hline
\end{tabular}

${ }^{\text {a }}$ Structure 7 had to be excluded from the analysis because of a different $\mathrm{UL}_{\mathrm{Ll}}\left(2^{\prime}-\mathrm{OH}\right)$ group orientation between the $\mathrm{QM} / \mathrm{MM}$ - and MM-optimized structures. ${ }^{\mathrm{b}} \Delta \mathrm{d}_{\mathrm{QM} / \mathrm{MM}}=\mathrm{QM} / \mathrm{MM}-$ initial value, ${ }^{\mathrm{c}} \Delta \mathrm{d}_{\mathrm{MM}}=\mathrm{MM}-$ initial value, ${ }^{\mathrm{d}} \Delta \mathrm{d}_{1}=\mathrm{MM}-\mathrm{QM} / \mathrm{MM}$. 
Table S14. Comparison of QM- and MM-optimized UUCG TLs using implicit solvent calculations. The analyzed features are the $\mathrm{G}_{\mathrm{S}+1}(\mathrm{C} 8 \mathrm{H} 8) \ldots \mathrm{G}_{\mathrm{S}+1}\left(\mathrm{O} 5{ }^{\prime}\right) \mathrm{H} . . . \mathrm{O}$ distance describing $0 \mathrm{BPh}$ interaction, the $\mathrm{U}_{\mathrm{L} 2}\left(\mathrm{O} 2^{\prime}\right)-\mathrm{U}_{\mathrm{L} 2}\left(\mathrm{O} 2^{\prime} \mathrm{H}\right)-\mathrm{G}_{\mathrm{L} 4}(\mathrm{~N} 7) \mathrm{O}-\mathrm{H} \ldots \mathrm{N}$ angle describing $\mathrm{U}_{\mathrm{L} 2}\left(2^{\prime}\right.$ $\mathrm{OH}) \ldots \mathrm{G}_{\mathrm{L} 4}(\mathrm{~N} 7)$ signature H-bond, and the $\mathrm{U}_{\mathrm{L} 1}\left(\mathrm{O} 2^{\prime}\right)-\mathrm{G}_{\mathrm{L} 4}(\mathrm{O} 6)$ donor-acceptor and $\mathrm{U}_{\mathrm{L} 1}\left(\mathrm{O} 2^{\prime} \mathrm{H}\right)$ $\mathrm{G}_{\mathrm{L} 4}(\mathrm{O} 6)$ hydrogen-acceptor distances describing $\mathrm{U}_{\mathrm{L} 1}\left(2^{\prime}-\mathrm{OH}\right) \ldots \mathrm{G}_{\mathrm{L} 4}(\mathrm{O} 6)$ signature H-bond. ${ }^{\mathrm{a}, \mathrm{b}}$

\begin{tabular}{|c|c|c|c|c|}
\hline & Start & QM & MM & $\mathrm{MM}-\mathrm{QM}$ \\
\hline \multicolumn{5}{|c|}{$\mathrm{G}_{\mathrm{s}+1}(\mathrm{C} 8 \mathrm{H} 8) \ldots \mathrm{Gs}+1\left(\mathrm{O}^{\prime}\right) \mathrm{H} \ldots \mathrm{O}$ distance $(\text { in } \AA)^{\mathrm{c}}$} \\
\hline structure 6 & 2.18 & 2.29 & 2.45 & 0.16 \\
\hline structure 7 & 2.39 & 2.31 & 2.39 & 0.08 \\
\hline structure 9 & 2.15 & 2.27 & 2.39 & 0.12 \\
\hline \multicolumn{5}{|c|}{$\mathrm{U}_{\mathrm{L} 2}\left(\mathrm{O} 2^{\prime}\right)-\mathrm{U}_{\mathrm{L} 2}\left(\mathrm{O} 2^{\prime} \mathrm{H}\right)-\mathrm{G}_{\mathrm{L} 4}(\mathrm{~N} 7)$ angle $\left(\text { in }^{\circ}\right)^{\mathrm{d}}$} \\
\hline structure 1 & 143.4 & 167.7 & 139.3 & -28.4 \\
\hline structure 2 & 118.1 & 167.8 & 137.5 & -30.3 \\
\hline structure 4 & 140.8 & 167.1 & 139.7 & -27.4 \\
\hline structure 5 & 161.6 & 167.6 & 139.6 & -28.0 \\
\hline \multicolumn{5}{|c|}{$\mathrm{UL}_{\mathrm{L} 1}\left(2{ }^{\prime}-\mathrm{OH}\right) \ldots \mathrm{G} 44(\mathrm{O} 6) \mathrm{H}$-bond $\mathrm{O} \ldots \mathrm{O} / \mathrm{H} \ldots \mathrm{O}$ distances $(\text { in } \AA)^{\mathrm{e}}$} \\
\hline structure 1 & $2.61 / 1.70$ & $2.64 / 1.68$ & $2.69 / 1.71$ & $0.05 / 0.03$ \\
\hline structure 2 & $2.64 / 1.79$ & $2.64 / 1.68$ & $2.68 / 1.70$ & $0.04 / 0.03$ \\
\hline structure 4 & $2.74 / 1.80$ & $2.65 / 1.69$ & $2.68 / 1.70$ & $0.02 / 0.01$ \\
\hline structure 5 & $2.70 / 1.76$ & $2.64 / 1.68$ & $2.69 / 1.71$ & $0.04 / 0.03$ \\
\hline
\end{tabular}

${ }^{a}$ The PBEh-3c (QM) and ff99bsc0 $\chi_{\mathrm{OL} 3}(\mathrm{MM})$ methods using implicit solvent (COSMO and GB for QM and MM, respectively) were used for geometry optimizations. ${ }^{\mathrm{b}}$ Structures 3, $\mathbf{6}$ and $\mathbf{9}$ are not included in the analyses because of formation of the spurious $\mathrm{U}_{\mathrm{L} 2}\left(\mathrm{O} 2^{\prime} \mathrm{H}\right) \ldots \mathrm{C}_{\mathrm{L} 3}\left(\mathrm{O} 4^{\prime}\right) \mathrm{H}$-bond after $\mathrm{MM} / \mathrm{GB}$ optimization. ${ }^{\mathrm{c}}$ Only structures with the native $\mathrm{G}_{s+1}$ phosphate, i.e., possessing the $0 \mathrm{BPh}$ interaction, were used for this analysis. ${ }^{\mathrm{d}}$ Structures $\mathbf{7}$ and $\mathbf{8}$ are not included in this analysis because spurious state of the $\mathrm{U}_{\mathrm{L} 1}\left(2^{\prime}-\mathrm{OH}\right)$ group is present in these structures, which may possibly influence position of the $\mathrm{G}_{\mathrm{L} 4}$ nucleobase and subsequently the $\mathrm{U}_{\mathrm{L} 2}\left(2^{\prime}-\mathrm{OH}\right) \ldots \mathrm{G}_{\mathrm{L} 4}(\mathrm{~N} 7) \mathrm{H}-$ bond. ${ }^{\mathrm{e}}$ Structures $\mathbf{7}$ and $\mathbf{8}$ are not included in this analysis because spurious state of the $\mathrm{U}_{\mathrm{L} 1}\left(2^{\prime}-\mathrm{OH}\right)$ group is present in these structures, i.e., the $\mathrm{U}_{\mathrm{L} 1}(2$ '-OH $)$... G $\mathrm{G}_{\mathrm{L}}(\mathrm{O} 6) \mathrm{H}$-bond is not formed.

Table S15. The $\mathrm{G}_{\mathrm{L} 4}$ nucleobase position relatively to $\mathrm{G}_{\mathrm{S}+1}$ nucleobase after QM (PBEh-3c) and MM (ff99bsc0 $\left.\chi_{\mathrm{OL} 3}\right)$ geometry optimization in implicit solvent (COSMO and GB for QM and $\mathrm{MM}$, respectively) for structures 1, 2, 4 and 5. All these analyzed structures possess flipped $\mathrm{G}_{\mathrm{S}+1}$ phosphate. ${ }^{\text {a }}$

\begin{tabular}{c|cccc}
\hline structure & $\mathbf{1}$ & $\mathbf{2}$ & $\mathbf{4}$ & $\mathbf{5}$ \\
\hline QM & tilted & tilted & tilted & tilted \\
MM & planar & planar & planar & planar \\
\hline
\end{tabular}

${ }^{a}$ Structures 3, 6 and 9 are not included in the analysis because of formation of a spurious $\mathrm{U}_{\mathrm{L} 2}\left(\mathrm{O} 2^{\prime} \mathrm{H}\right) \ldots \mathrm{C}_{\mathrm{L} 3}\left(\mathrm{O} 4^{\prime}\right) \mathrm{H}-$ bond after MM/GB optimization. Structures $\mathbf{7}$ and $\mathbf{8}$ are not included in this analysis because spurious state of the $\mathrm{U}_{\mathrm{L} 1}\left(2^{\prime}-\mathrm{OH}\right)$ group is present in these structures, which may possibly influence orientation of the G $\mathrm{L}_{4}$ nucleobase. 
Table S16. List of interactions that were modified by the gHBfix ${ }_{\text {NCG19 }}$ potential for the r(gcUUCGgc) TL.

\begin{tabular}{|c|c|c|c|}
\hline \multirow{2}{*}{$\begin{array}{l}\text { Interacting } \\
\text { groups }^{\mathrm{a}}\end{array}$} & \multicolumn{2}{|c|}{ Bias (kcal/mol) } & \multirow{2}{*}{ H-bonds affected } \\
\hline & Support & Weakening & \\
\hline $\mathrm{NH} \ldots \mathrm{N}$ & 0.5 & - & N1H/N2H/N3H/N4H...N3/N7 \\
\hline NH...O & 0.5 & - & N1H/N2H/N3H/N4H...O2/O4/O6 \\
\hline $2-\mathrm{OH} \ldots \mathrm{N}$ & 0.5 & - & $2^{\prime}-\mathrm{OH} / 3^{\prime}-\mathrm{OH} / 5^{\prime}-\mathrm{OH} \ldots \mathrm{N} 3 / \mathrm{N} 7$ \\
\hline 2-OH...O & 0.5 & - & 2'-OH/3'-OH/5'-OH...O2/O4/O6 \\
\hline $2-\mathrm{OH} \ldots \mathrm{bO}$ & - & 0.5 & $2^{\prime}-\mathrm{OH} / 3^{\prime}-\mathrm{OH} / 5^{\prime}-\mathrm{OH} \ldots{ }^{\prime} .3^{\prime} / \mathrm{O} 5^{\prime}$ \\
\hline $2-\mathrm{OH} \ldots \mathrm{nbO}$ & - & 0.5 & $2^{\prime}-\mathrm{OH} / 3^{\prime}-\mathrm{OH} / 5^{\prime}-\mathrm{OH}$...pro- $\mathrm{R}_{\mathrm{P}} /$ pro- $\mathrm{S}_{\mathrm{P}}$ \\
\hline NH...O2 & - & 0.5 & $\mathrm{~N} 1 \mathrm{H} / \mathrm{N} 2 \mathrm{H} / \mathrm{N} 3 \mathrm{H} / \mathrm{N} 4 \mathrm{H} . . .2^{\prime}-\mathrm{OH} / 3^{\prime}-\mathrm{OH} / 5^{\prime}-\mathrm{OH}$ \\
\hline $2-\mathrm{OH} \ldots \mathrm{O} 4$ & - & 0.5 & 2'-OH/3'-OH/5'-OH...O4' \\
\hline $2-\mathrm{OH} \ldots \mathrm{O} 2$ & - & 0.5 & $2^{\prime}-\mathrm{OH} / 3^{\prime}-\mathrm{OH} / 5^{\prime}-\mathrm{OH} \ldots 2^{\prime}-\mathrm{OH} / 3^{\prime}-\mathrm{OH} / 5^{\prime}-\mathrm{OH}$ \\
\hline
\end{tabular}

${ }^{a}$ see Table 2 in ref. ${ }^{18}$ for the definition of interacting groups 


\section{S13. Supporting Figures}

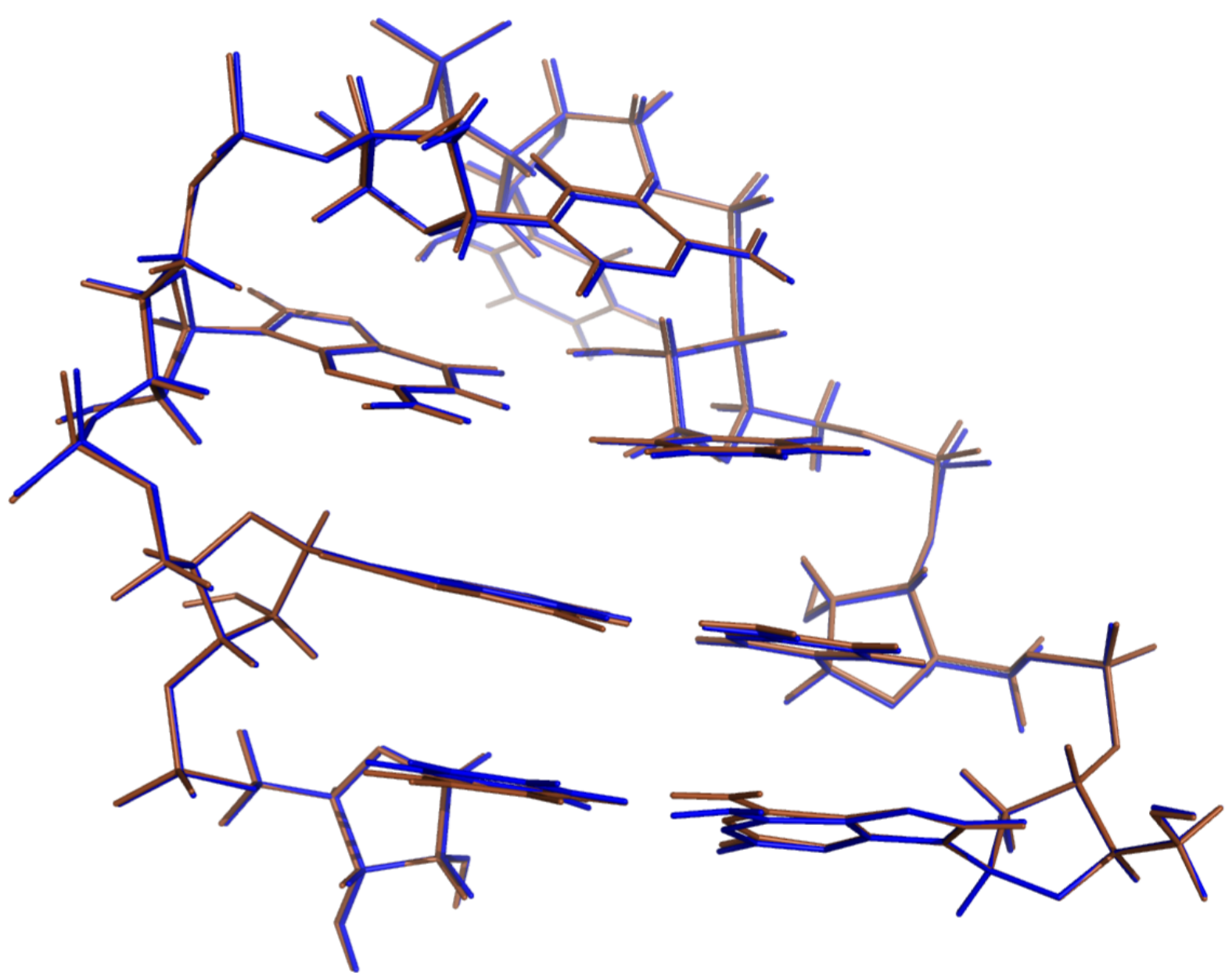

Figure S1. Overlay of the MM-optimized UUCG TL of structure 2 with or without vdW modification of phosphate oxygens $(\mathrm{CP}),{ }^{29}$ i.e. with $\mathrm{CP}$ (blue) and without $\mathrm{CP}$ (brown). 

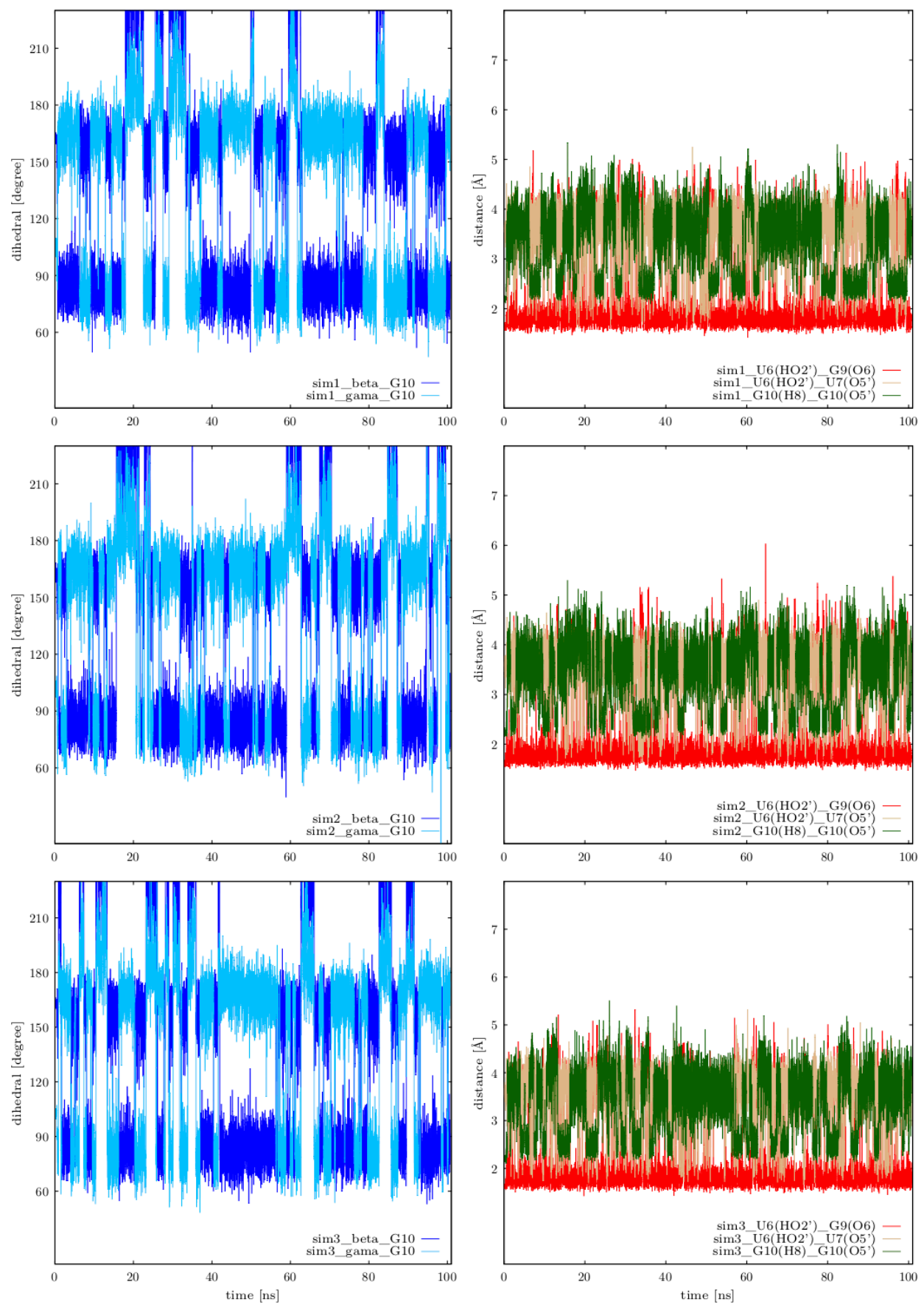

Figure S2. Occurrence of the alternative (flipped) $\mathrm{G}_{\mathrm{S}+1}$ phosphate state in three MD simulations (marked sim1, sim2, sim3) during the initial 100 ns and its possible correlation with the $\mathrm{U}_{\mathrm{L} 2}\left(2^{\prime}\right.$ $\mathrm{OH})$ flipping. Native state of the $\mathrm{G}_{\mathrm{S}+1}$ phosphate (labelled as G10 in panels) is described by $\beta_{\text {trans }} / \gamma_{g^{+}}$dihedrals (left panels) or by presence of the $0 \mathrm{BPh}$ interaction, i.e. the $\mathrm{G}_{\mathrm{S}+1}(\mathrm{C} 8 \mathrm{H} 8) \ldots \mathrm{G}_{\mathrm{S}+1}\left(\mathrm{O} 5{ }^{\prime}\right) \mathrm{H} . . . \mathrm{O}$ distance below $2.5 \AA$ (green line, panels on the right). The $\chi_{\mathrm{OL} 3 \mathrm{CP}}$ + gHBfix19 ff version (see Methods in the main text) was used. PDB (2KOC) numbering of nucleotides from 1 to 14 is used in the panels. 

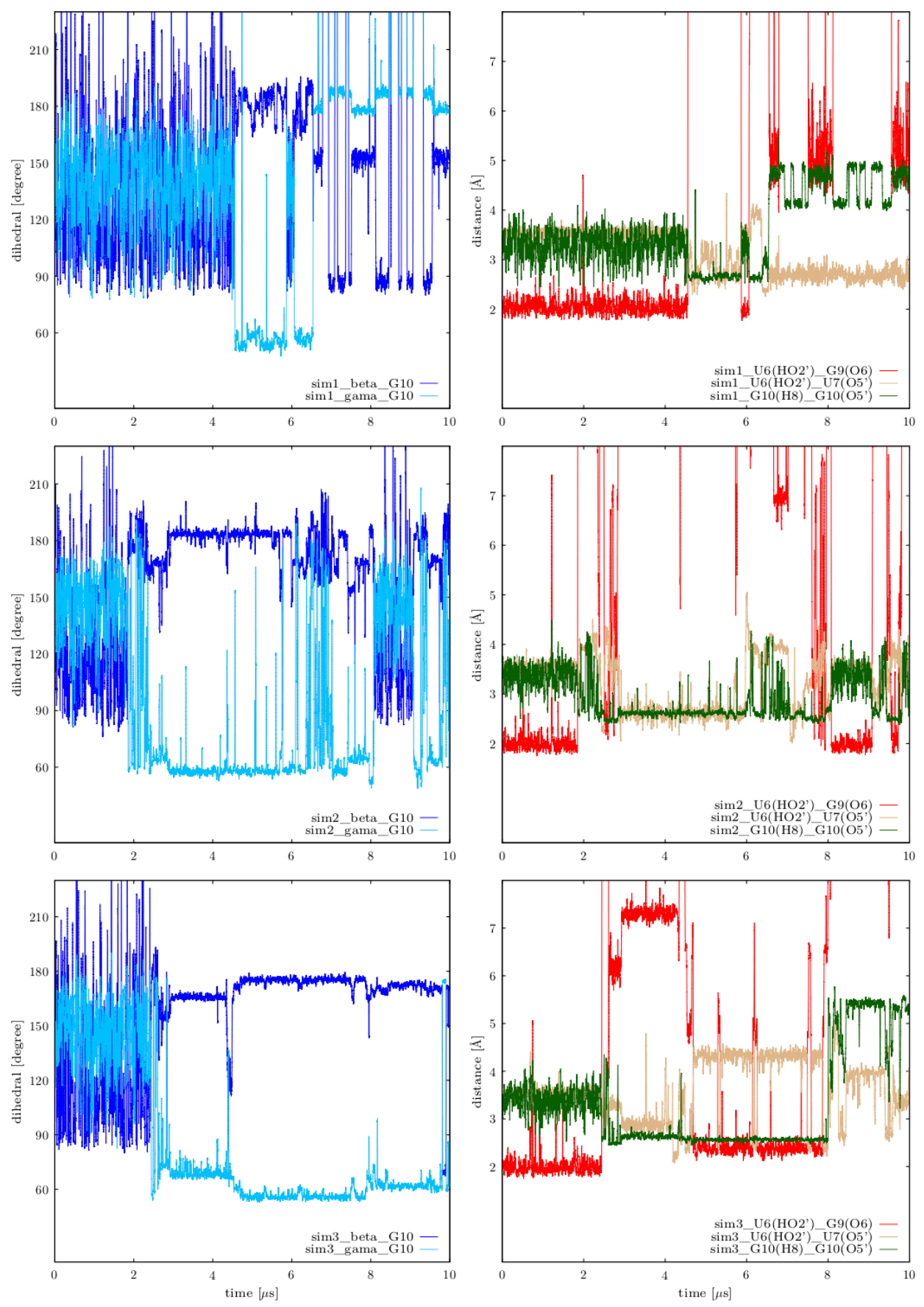

Figure S3. Occurrence of the alternative (flipped) $\mathrm{G}_{\mathrm{S}+1}$ phosphate state in three $10 \mu$ s long MD simulations of the r(ggcacUUCGgugcc) 14-mer and possible correlation with the $\mathrm{U}_{\mathrm{L} 2}(2$ '-OH) flipping. Native state of the $\mathrm{G}_{\mathrm{S}+1}$ phosphate is described by $\beta_{\text {trans }} / \gamma_{g^{+}}$dihedrals (left panels) or by presence of the $0 \mathrm{BPh}$ interaction, i.e. the $\mathrm{G}_{\mathrm{s}+1}(\mathrm{C} 8 \mathrm{H} 8) \ldots \mathrm{G}_{\mathrm{s}+1}\left(\mathrm{O} 5{ }^{\prime}\right) \mathrm{H} . . . \mathrm{O}$ distance below $2.5 \AA$ (panels on the right). Note that the figure is similar to Figure S2, but MD simulations are longer ( $\mu$ s compared to ns time-scale). Thus, disruption of the loop is observed after $4.6 \mu$ s for simulation 1 ( $\operatorname{sim} 1), \sim 1.8 \mu \mathrm{s}$ for simulation $2(\operatorname{sim} 2)$ and $\sim 2.4 \mu$ s for simulation 3 ( $\operatorname{sim} 3)$. The $\chi_{\mathrm{OL} 3 \mathrm{CP}}+\mathrm{gHBfix} 19 \mathrm{ff}$ version was used. PDB (2KOC) numbering of nucleotides from 1 to 14 is used in the panels. 

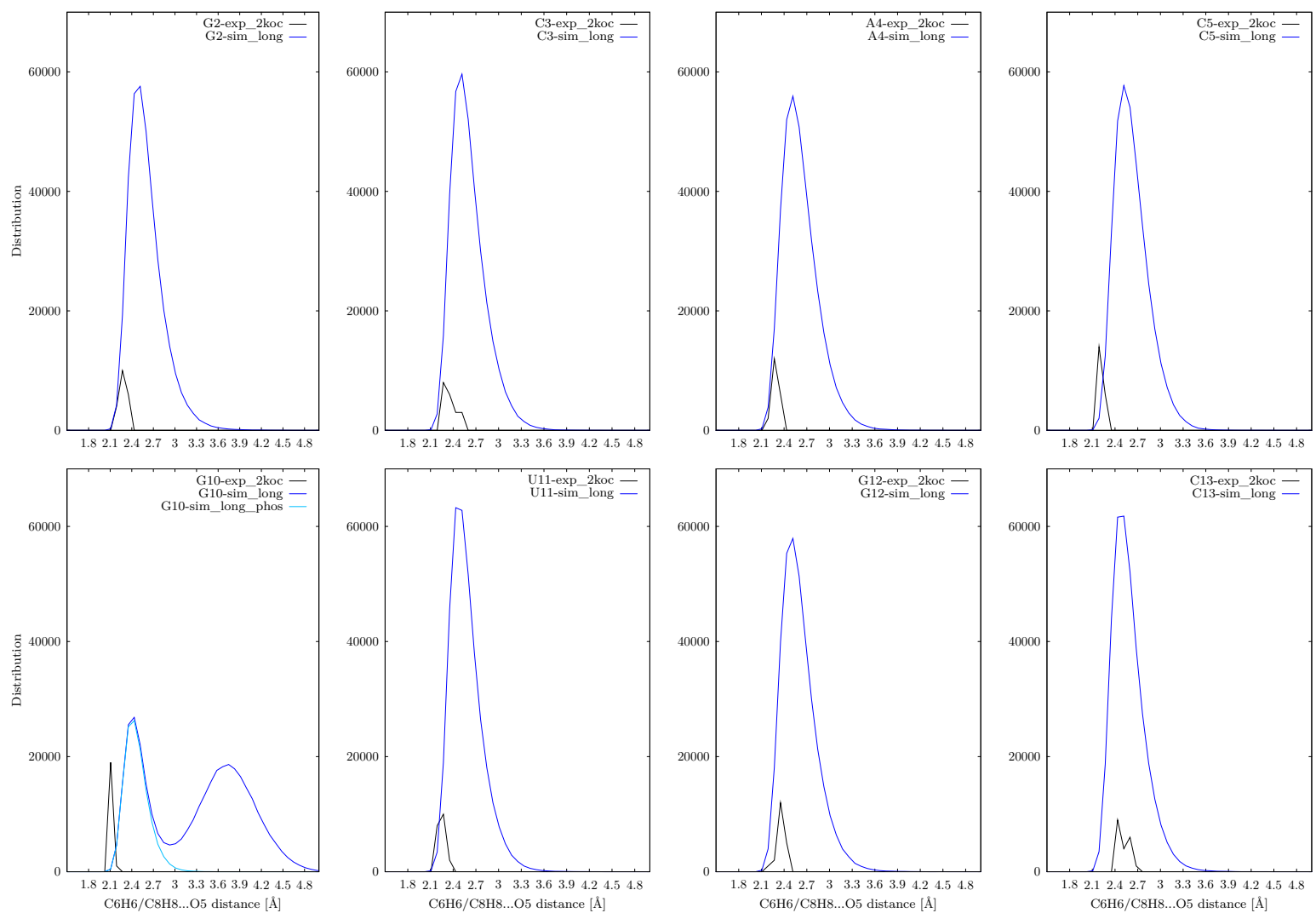

Figure S4. Distribution of $\mathrm{C} 8 \mathrm{H} 8 / \mathrm{C} 6 \mathrm{H} 6 \ldots \mathrm{O}^{\prime}$ ' distances (0BPh interaction) in MD simulation of the $\mathrm{r}$ (ggcacUUCGgugcc) 14-mer using the $\chi_{\mathrm{OL} 3 \mathrm{CP}}+$ gHBfix $19 \mathrm{ff}$ (blue lines). We analyzed only $4.6 \mu$ s-long part of MD trajectory before the disruption of the loop occurred, see sim 1 in Figure S3). There are two states observed for $\mathrm{G}_{\mathrm{S}+1}$ (first column, second row; $\mathrm{G}_{\mathrm{S}+1}$ is labelled as G10 in the bottom left panel) corresponding to native and flipped $\mathrm{G}_{\mathrm{S}+1}$ phosphate, i.e., presence or absence of the $0 \mathrm{BPh}$ interaction, respectively. Black lines show distributions in the experimental structure (20 NMR models, PDB ID 2KOC). PDB (2KOC) numbering of nucleotides from 1 to 14 is used in the panels. 


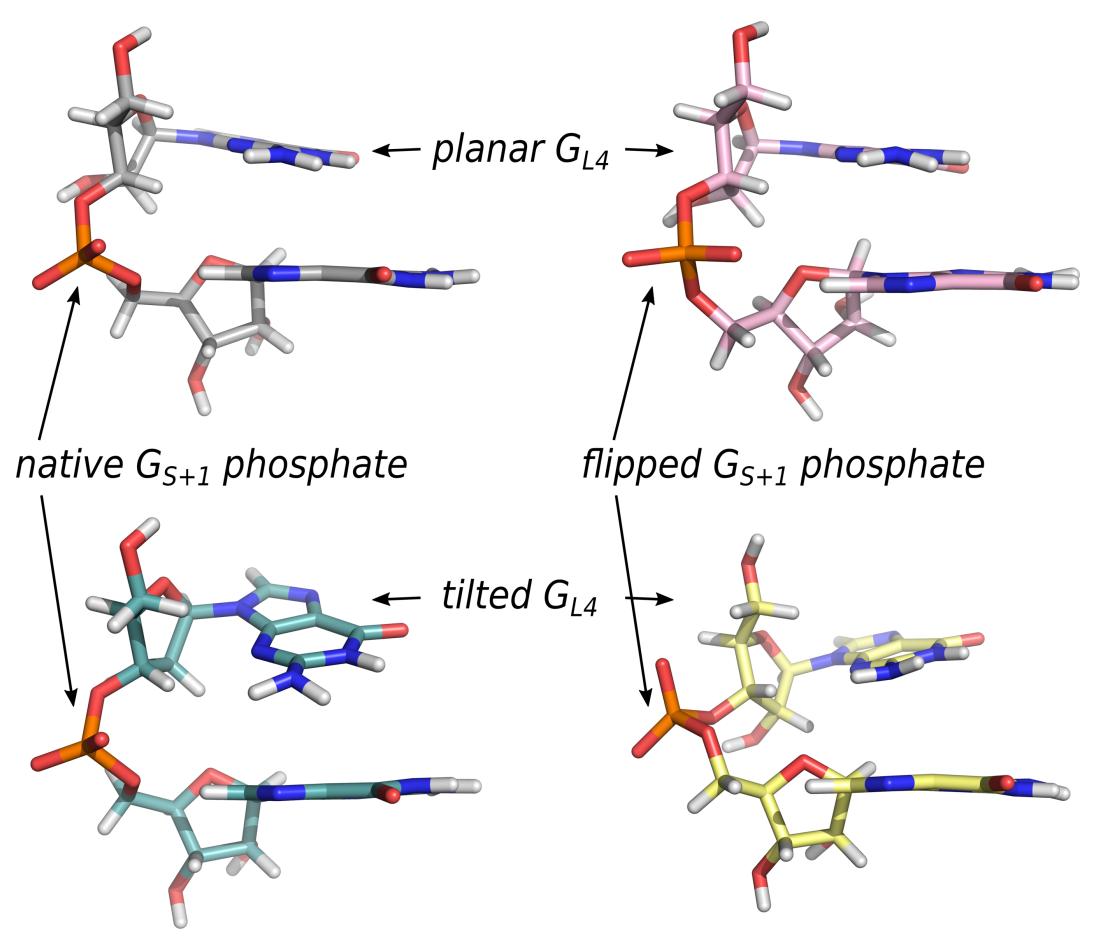

Figure S5. The four dinucleoside monophosphate models representing four combinations of the $\mathrm{G}_{\mathrm{L} 4}$ nucleobase (planar or tilted) and $\mathrm{G}_{\mathrm{S}+1}$ phosphate (native or flipped) states.

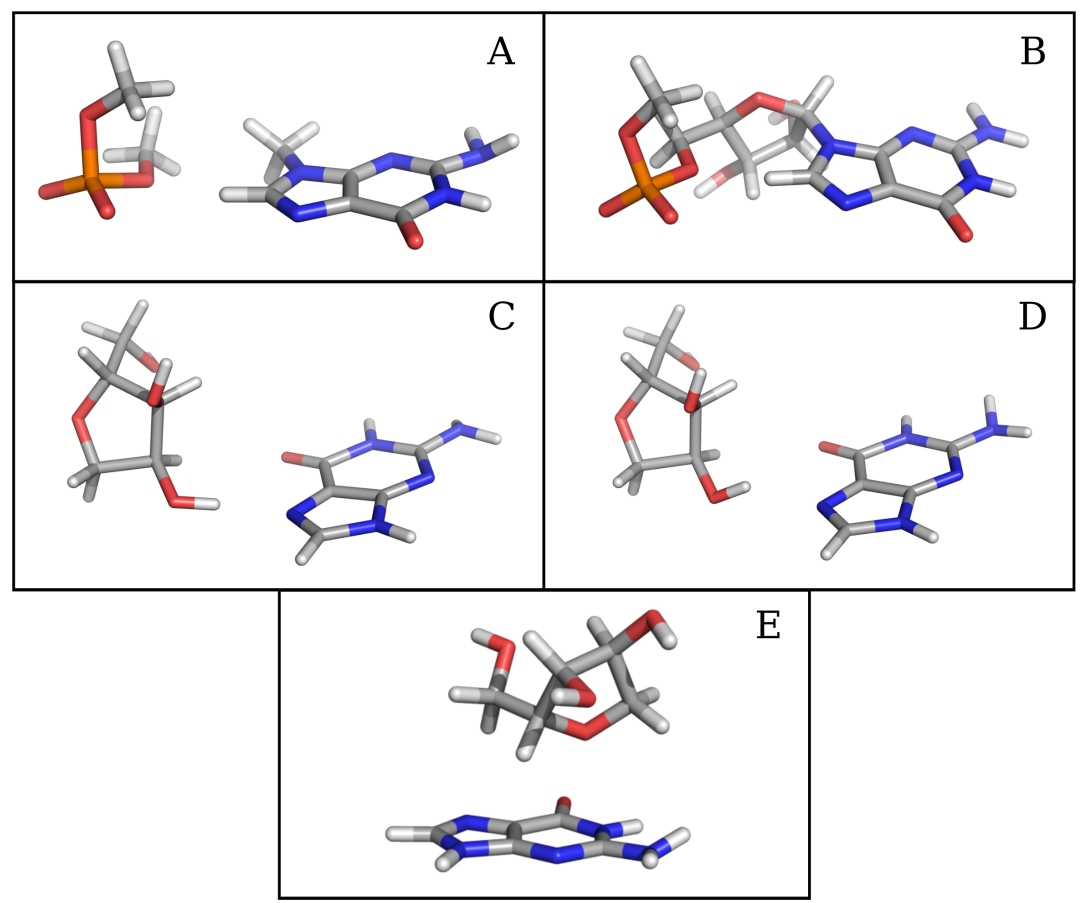

Figure S6. Models used for scans describing the $0 \mathrm{BPh}$ interaction (first row) dimethyl-phosphate - methylguanine molecular complex (A) and O3'-methylated-guanosine-monophosphate unit 
(B), models used for scans describing $\mathrm{U}_{\mathrm{L} 2}\left(2^{\prime}\right.$ '-OH)... $\mathrm{G}_{\mathrm{L} 4}(\mathrm{~N} 7) \mathrm{H}$-bond (second row) with O-H...N angle equal to $170^{\circ}(\mathbf{C})$ and $143^{\circ}(\mathbf{D})$, and model used for the scan describing ribose-base stacking (E).

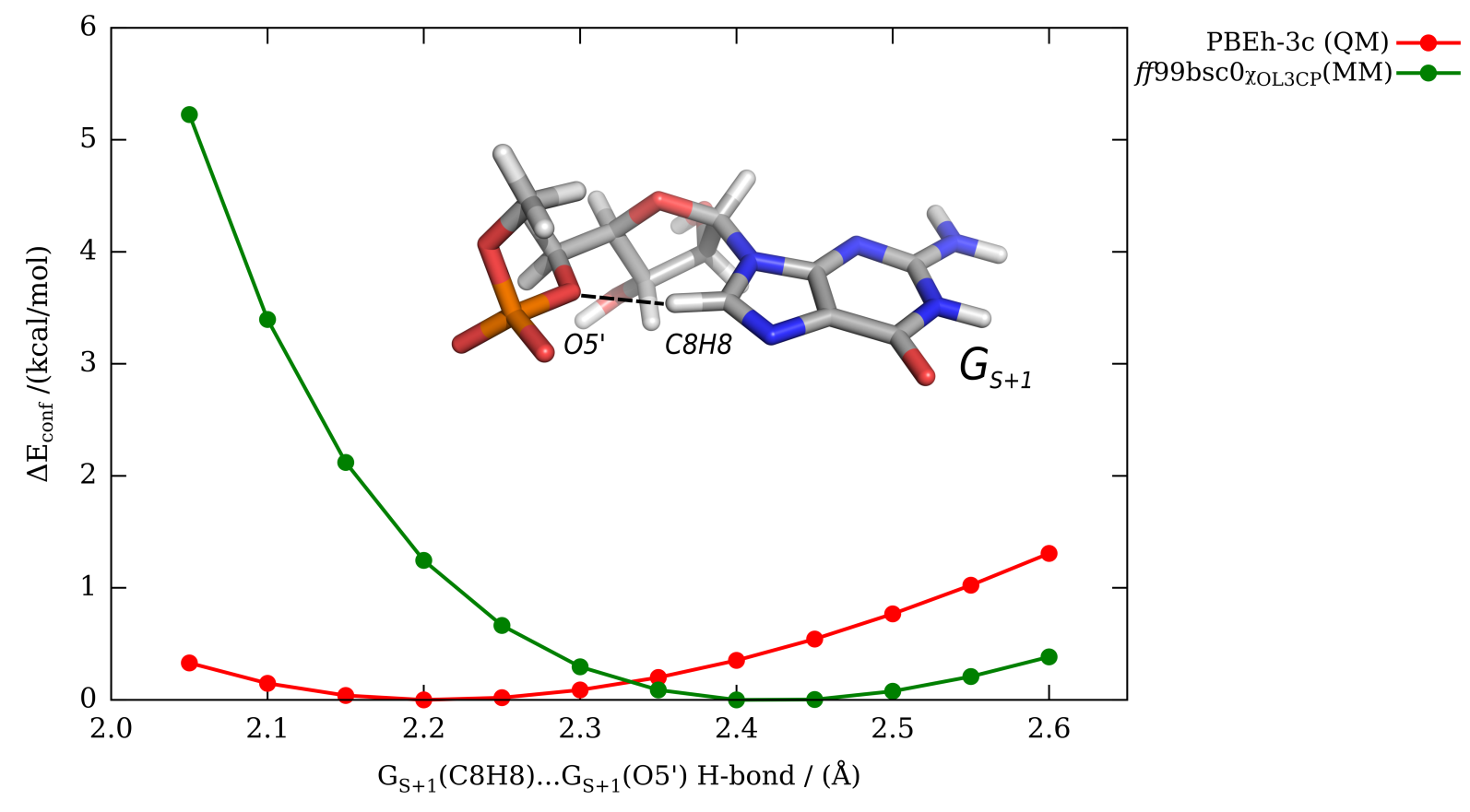

Figure S7. Conformational energy scan along the $\mathrm{G}_{\mathrm{S}+1}(\mathrm{C} 8 \mathrm{H} 8)$... $\mathrm{G}_{\mathrm{S}+1}\left(\mathrm{O} 5^{\prime}\right)$ distance describing the $0 \mathrm{BPh}$ interaction using $\mathrm{QM}$ (PBEh-3c; red) and $\mathrm{MM}$ (ff99bsc0 $\chi_{\mathrm{OL} 3 \mathrm{CP}}$; green) methods performed on the $\mathrm{O} 3$ '-methylated-guanosine-monophosphate model. 

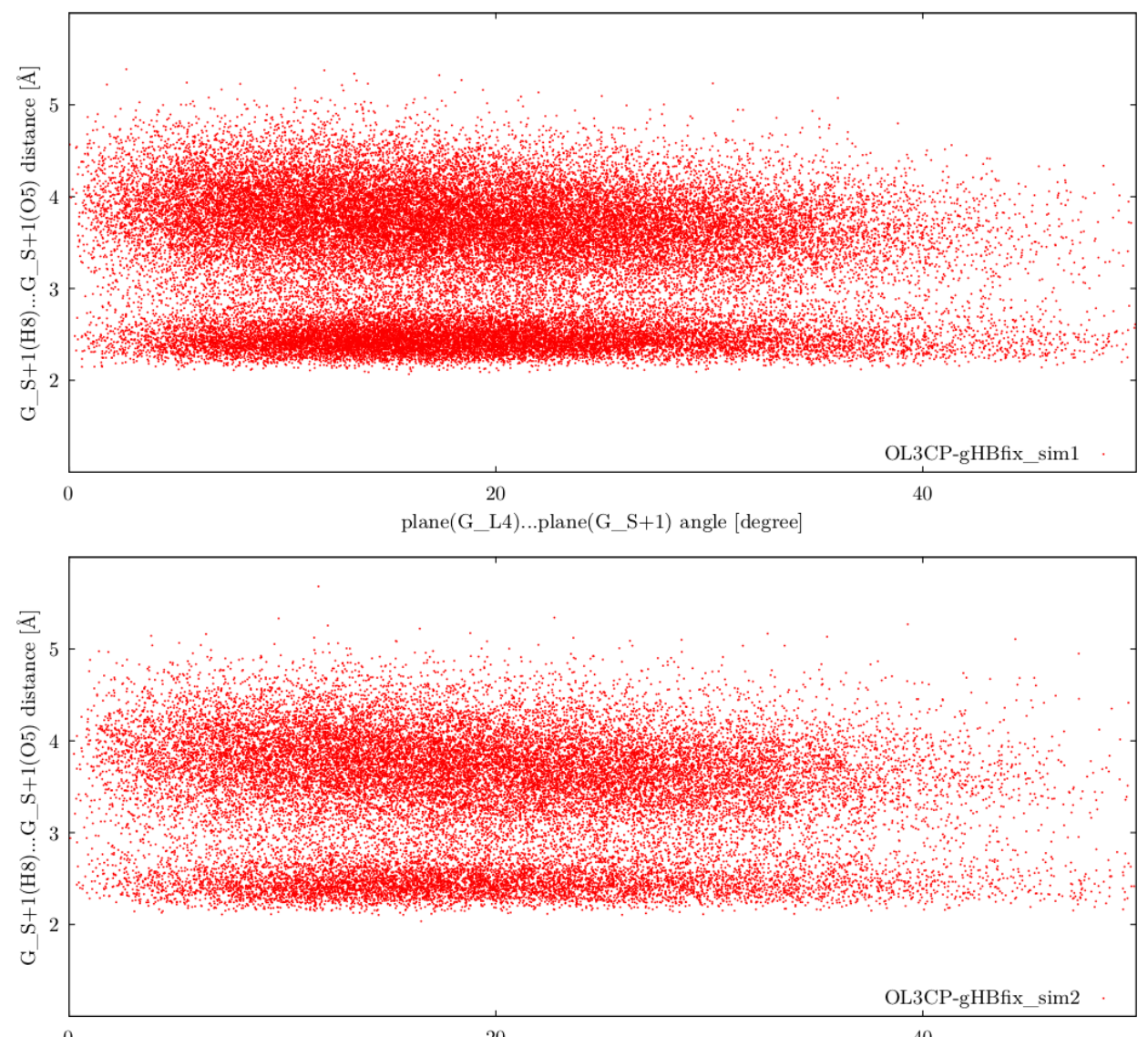

plane(G_L4)...plane(G_S+1) angle [degree]

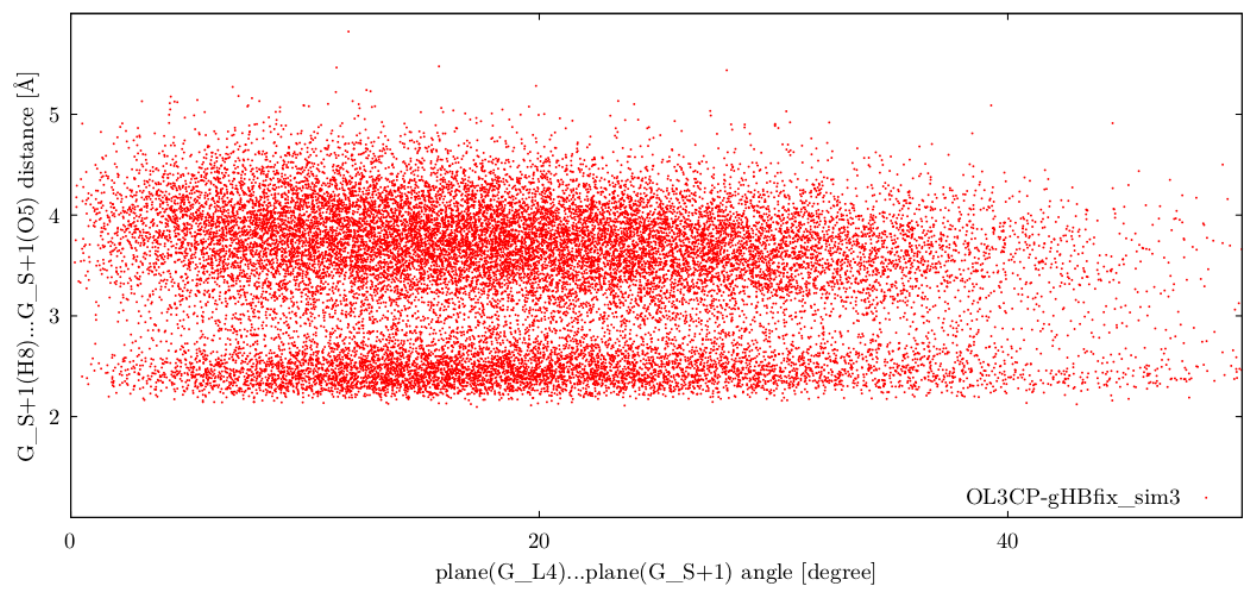

Figure S8. Relationship between the $0 \mathrm{BPh}$ interaction represented by the

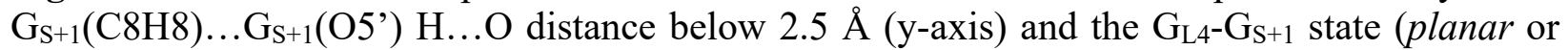
tilted) represented by the angle between planes defined by $\mathrm{G}_{\mathrm{L} 4}$ and $\mathrm{G}_{\mathrm{S}+1}$ nucleobases (x-axis). Only $\sim 4.6 \mu$ s-long (sim 1 ), $\sim 1.8 \mu$ s-long ( $\operatorname{sim} 2$ ) and $\sim 2.4 \mu$ s-long (sim3) parts of three MD trajectories were analyzed (see Figure S3). 

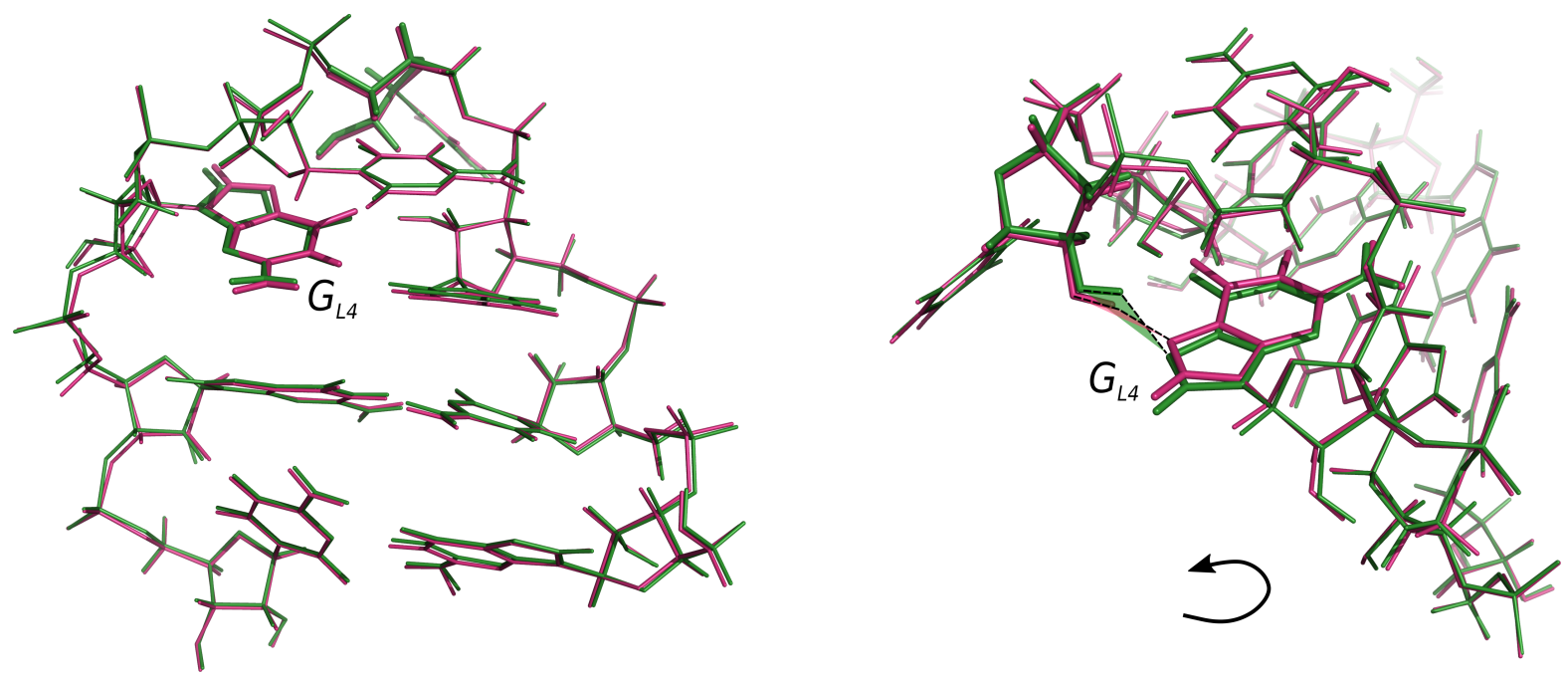

Figure S9. UUCG TL structure 6 optimized at QM/MM (PBEh-3c; pink) and MM (ff $99 \mathrm{bsc} 0 \chi_{\mathrm{OL} 3}$; green) levels of theory. The Figure shows insufficient description of $\mathrm{U}_{\mathrm{L} 2}(2$ '$\mathrm{OH}) \ldots \mathrm{G}_{\mathrm{L}}(\mathrm{N} 7)$ signature H-bond by the MM, which is even visually visible on the right part.

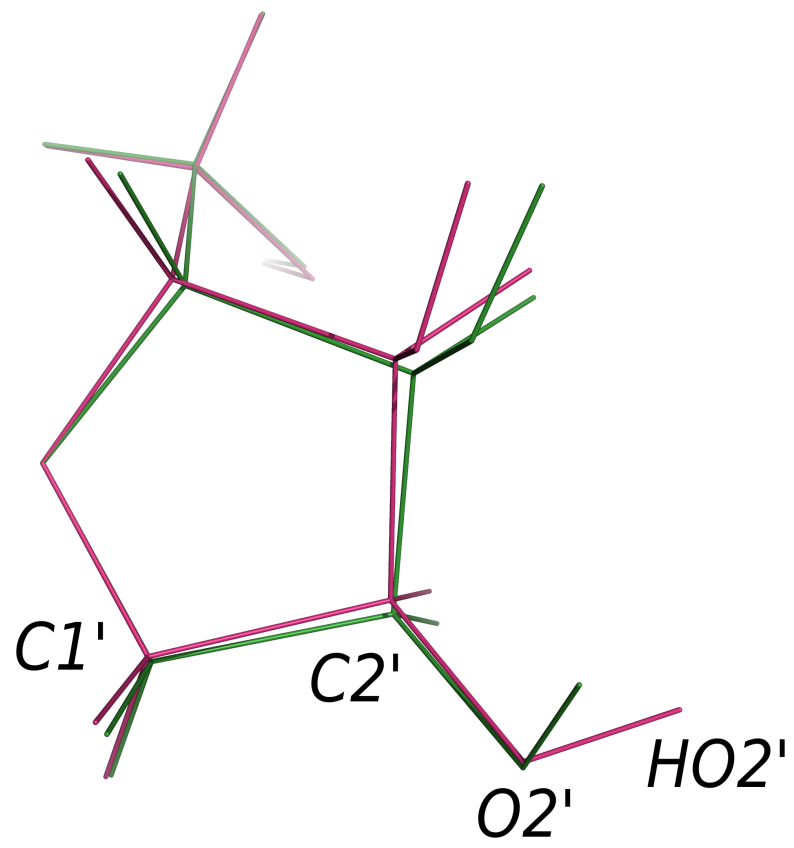

Figure S10. Model of the QM (PBEh-3c; pink) and MM (ff $99 \mathrm{bsc} 0_{\mathrm{CP}}$; green) optimized ribose. 


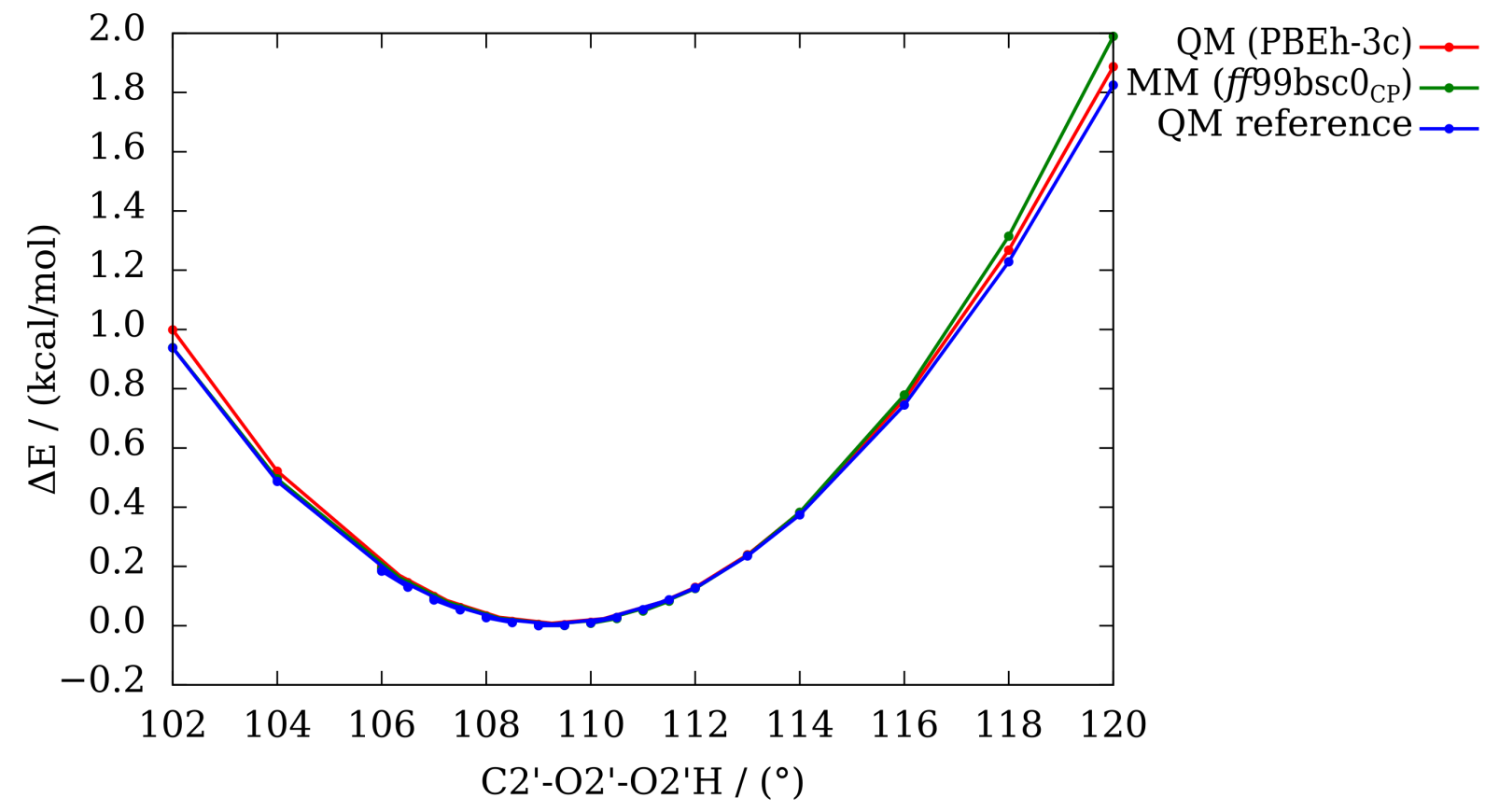

Figure S11. Conformational energy profile of the $\mathrm{U}_{\mathrm{L} 2}$ ribose along the $\mathrm{C} 2$ '-O2'-O2'H angle using QM (PBEh-3c; red), MM (ff99bsc0; green) and QM reference (DLPNO-CCSD(T)/CBS; blue) methods. The reference point (zero energy) refers to the C2'-O2'-O2'H angle of the QMoptimized ribose $\left(109.3^{\circ}\right)$. 


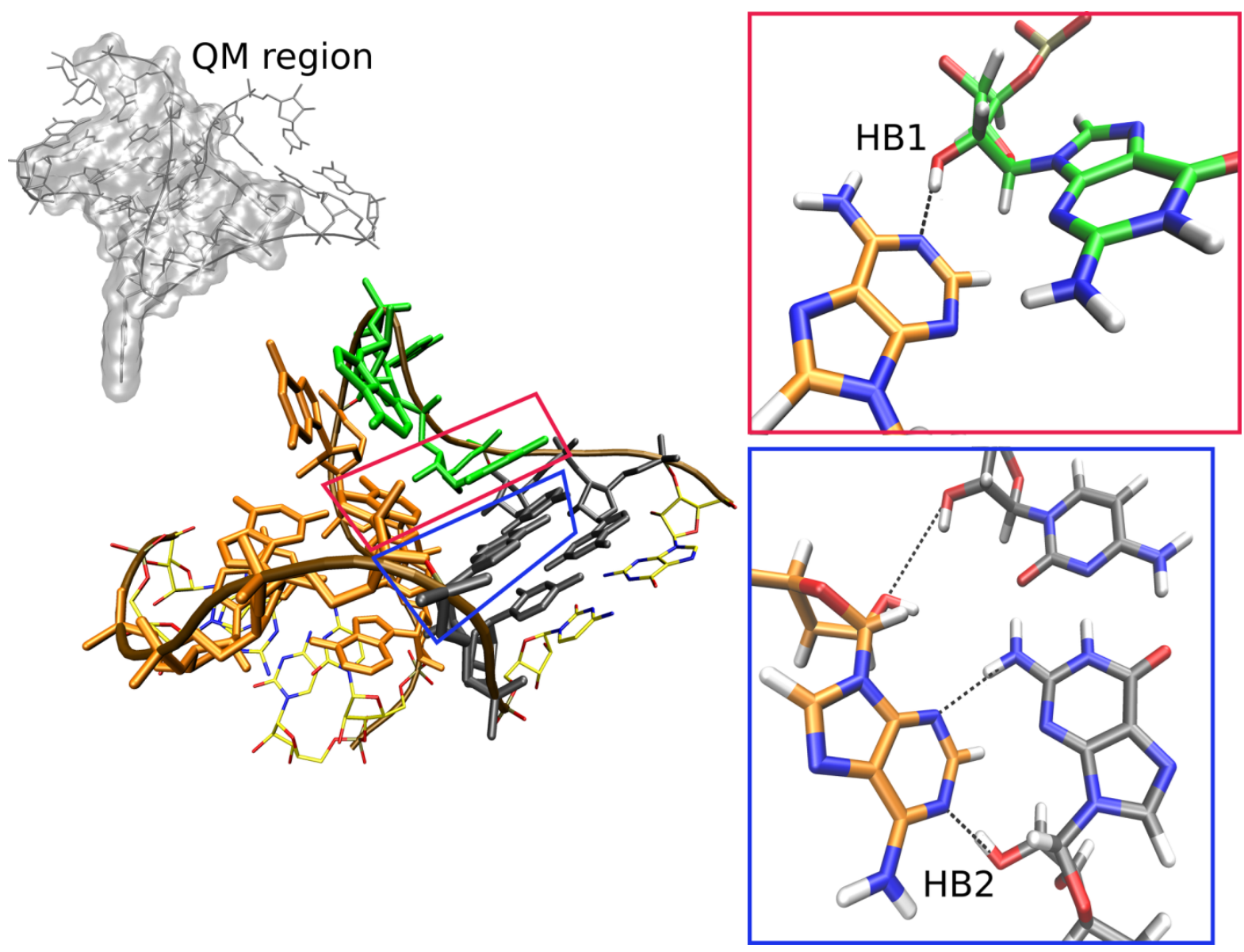

Figure S12. 3D representation of the Kt-7 structure, with the canonical and non-canonical stems, and the bulge, in grey, orange, and green, respectively. The RNA backbone is traced in brown. The A-minor interaction and the kink-turn signature interaction are highlighted in blue and red, respectively and their details displayed in insets on the right. The grey Figure upper left depicts segment of the molecule included in QM region of the QM/MM calculations. The dashed black lines (right) indicate H-bonds. 


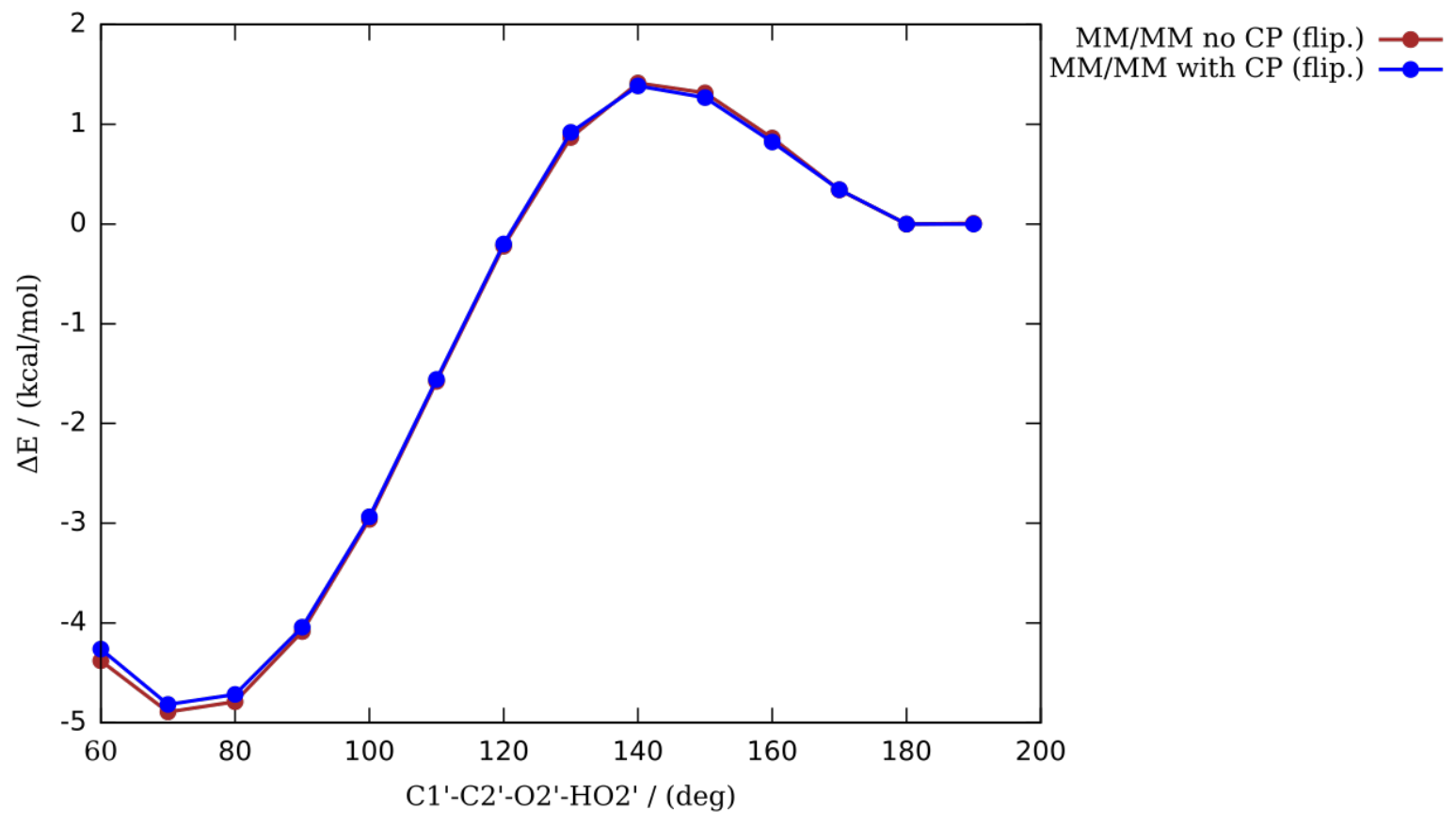

Figure S13. MM/MM conformation energy scan for structure $\mathbf{8}$ with and without the modified $\mathrm{vdW}$ parameters for phosphate oxygens (CP). ${ }^{29}$ 

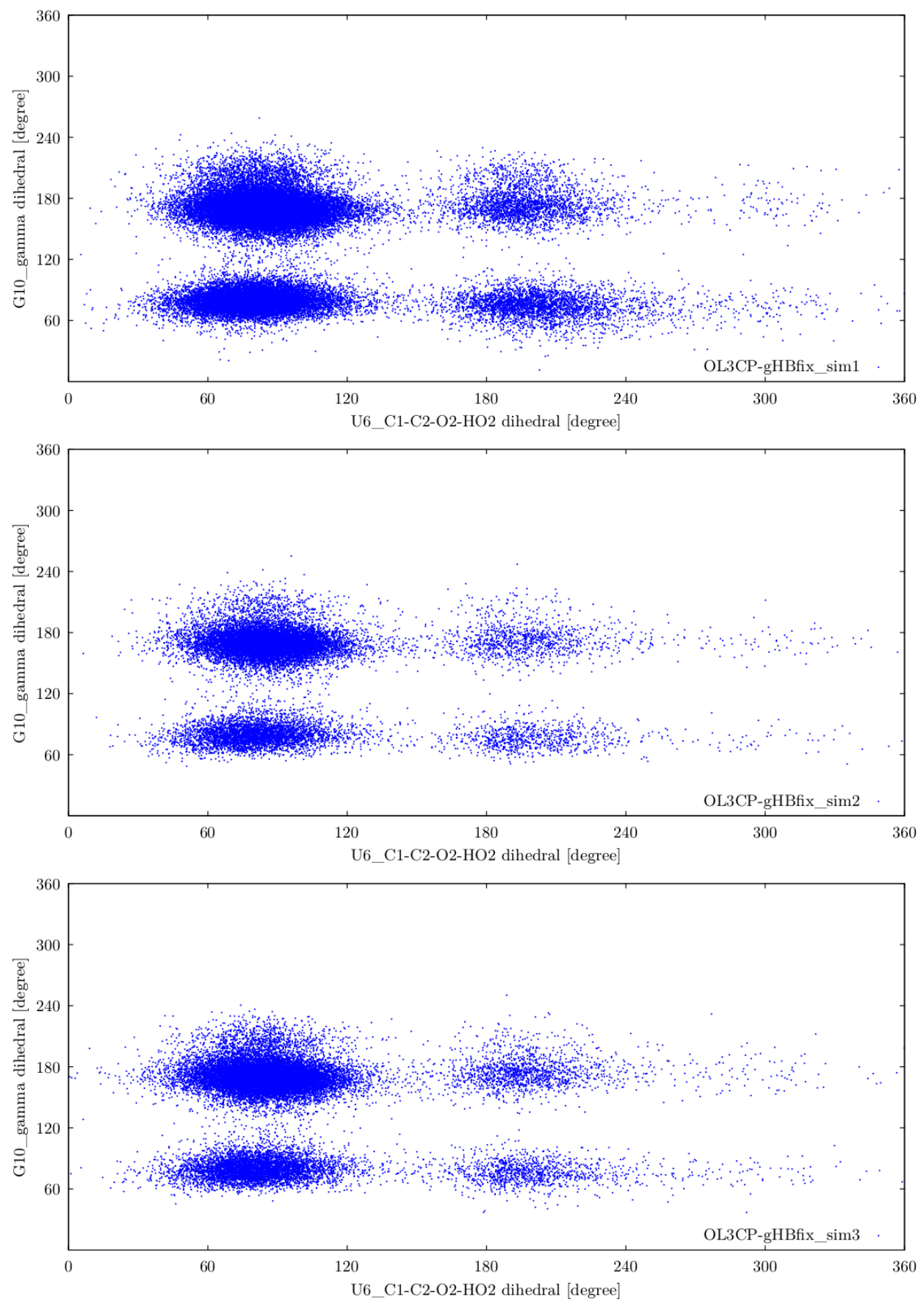

Figure S14. Correlation plot of $\mathrm{G}_{\mathrm{S}+1}$ phosphate conformation, i.e. native state $\left(\gamma \sim 60^{\circ}\right)$ or flipped state $\left(\gamma \sim 180^{\circ}\right)$, and $\mathrm{U}_{\mathrm{L} 1}\left(2^{\prime}-\mathrm{OH}\right)$ flipping, i.e. native orientation $\left(\mathrm{C}^{\prime}\right.$ '- $\mathrm{C} 2$ ' $-\mathrm{O} 2$ ' $\left.-\mathrm{O} 2{ }^{\prime} \mathrm{H} \sim 80^{\circ}\right)$ or flipped orientation $\left(\mathrm{C}^{\prime}-\mathrm{C}^{\prime}-\mathrm{O} 2^{\prime}-\mathrm{O} 2{ }^{\prime} \mathrm{H} \sim 180^{\circ}\right)$. Note that all four substates, i.e. native/flipped $\mathrm{G}_{\mathrm{S}+1}$ phosphate combined with native/flipped $\mathrm{U}_{\mathrm{L} 1}\left(2^{\prime}-\mathrm{OH}\right)$ were populated during $\mathrm{MD}$ simulations. $\mathrm{G}_{\mathrm{S}+1}$ nucleotide is labelled as G10 in panels. Only $4.6 \mu \mathrm{s}-$ long ( $\left.\operatorname{sim} 1\right), \sim 1.8 \mu \mathrm{s}-$ long ( $\operatorname{sim} 2)$ and $\sim 2.4 \mu$ s-long ( $\operatorname{sim} 3)$ parts of three MD trajectories were analyzed (see Figure S3). 


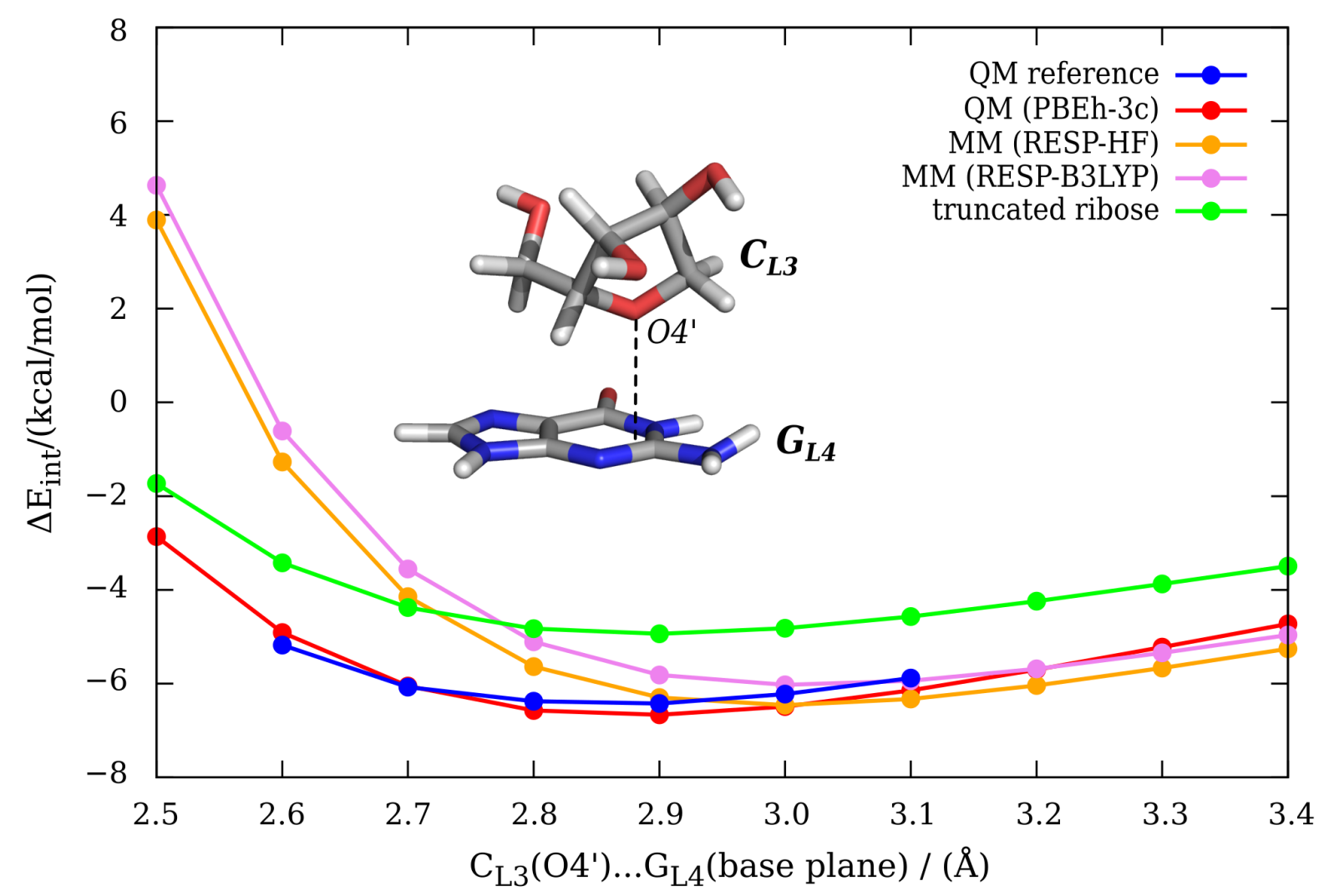

Figure S15. Interaction energy scans of the ribose-base stacking between the O4' atom of the $\mathrm{C}_{\mathrm{L} 3}$ ribose and the $\mathrm{G}_{\mathrm{L} 4}$ nucleobase plane. The MM method using two types of partial charges (RESP-HF, RESP-B3LYP; for more information see Section S4) is evaluated against the QM methods, i.e. PBEh-3c used in QM/MM optimizations of the UUCG TL and the DLPNO$\operatorname{CCSD}(\mathrm{T}) / \mathrm{CBS}$ method used as the reference. Optimal distances are 3.00 $\AA, 3.01 \AA, 2.88 \AA$ and $2.87 \AA$ for MM (RESP-HF), MM (RESP-B3LYP), QM (PBEh-3c) and QM reference, respectively, showing that MM overestimates the optimal distance by $\sim 0.13 \AA$. Interaction energies at the optimal distances are comparable between QM and MM methods, i.e., -6.46 $\mathrm{kcal} / \mathrm{mol},-6.03 \mathrm{kcal} / \mathrm{mol},-6.67 \mathrm{kcal} / \mathrm{mol}$ and $-6.43 \mathrm{kcal} / \mathrm{mol}$ for MM (RESP-HF), MM (RESPB3LYP), QM (PBEh-3c) and QM reference, respectively. Overestimation of the short-range repulsion by the Lennard-Jones MM is clearly seen. For the sake of completeness, we also tested another model having truncated ribose ring (used in ref. ${ }^{14}$ ). The smaller model system, i.e., with the truncated ribose, shows a weaker interaction energy $(-4.94 \mathrm{kcal} / \mathrm{mol})$ compared to the larger ribose-base model and the result is similar to ref. ${ }^{14}(-4.26 \mathrm{kcal} / \mathrm{mol})$. We note that the guanine base of the sugar-base model in ref. ${ }^{14}$ was restrained to be planar during geometry optimization, which should be the reason for the interaction energy difference of $0.68 \mathrm{kcal} / \mathrm{mol}$ within this two studies. 


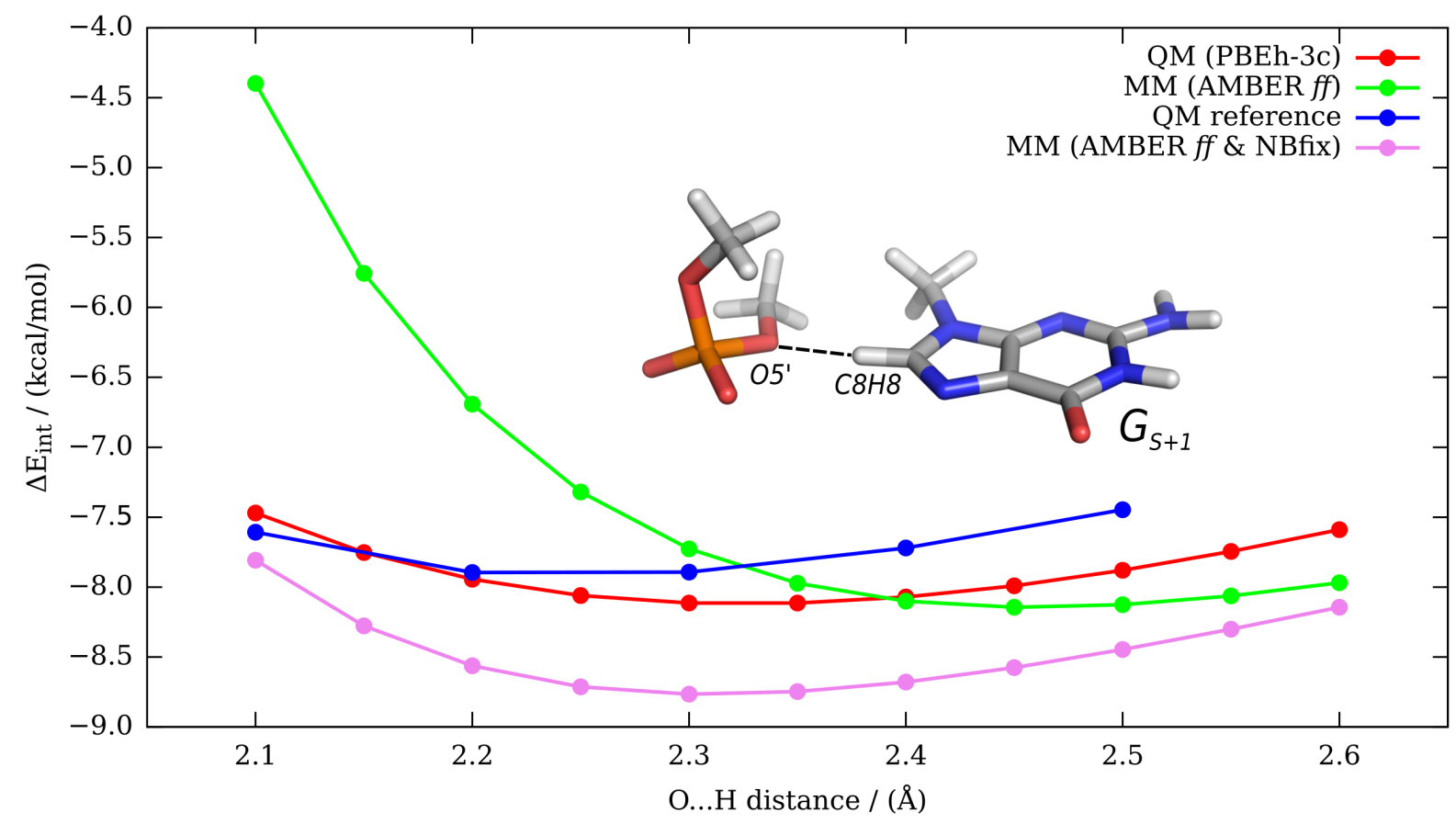

Figure S16. Comparison of the QM (PBEh-3c; red), MM (AMBER ff; green), QM reference (DLPNO-CCSD(T)/CBS; blue) and MM (AMBER ff with NBfix correction; see Section S4; purple) interaction energy profiles along the $\mathrm{G}_{\mathrm{S}+1}(\mathrm{C} 8 \mathrm{H} 8) \ldots \mathrm{G}_{\mathrm{S}+1}\left(\mathrm{O} 5{ }^{\prime}\right) \mathrm{H} \ldots \mathrm{O}$ distance of the dimethyl-phosphate - methyl-guanine model. Optimal distances are 2.32 $\AA, 2.46 \AA, 2.24 \AA$ and $2.32 \AA$ for $\mathrm{QM}, \mathrm{MM}, \mathrm{QM}$ reference and $\mathrm{MM}$ corrected by NBfix, respectively. The overestimation of the optimal $\mathrm{G}_{\mathrm{S}+1}(\mathrm{C} 8 \mathrm{H} 8) \ldots \mathrm{G}_{\mathrm{S}+1}(\mathrm{O} 5$ ') distance by the original MM potential (green) is corrected by the designed NBfix correction. Graph is extended version of the Figure 5 in the main text. 

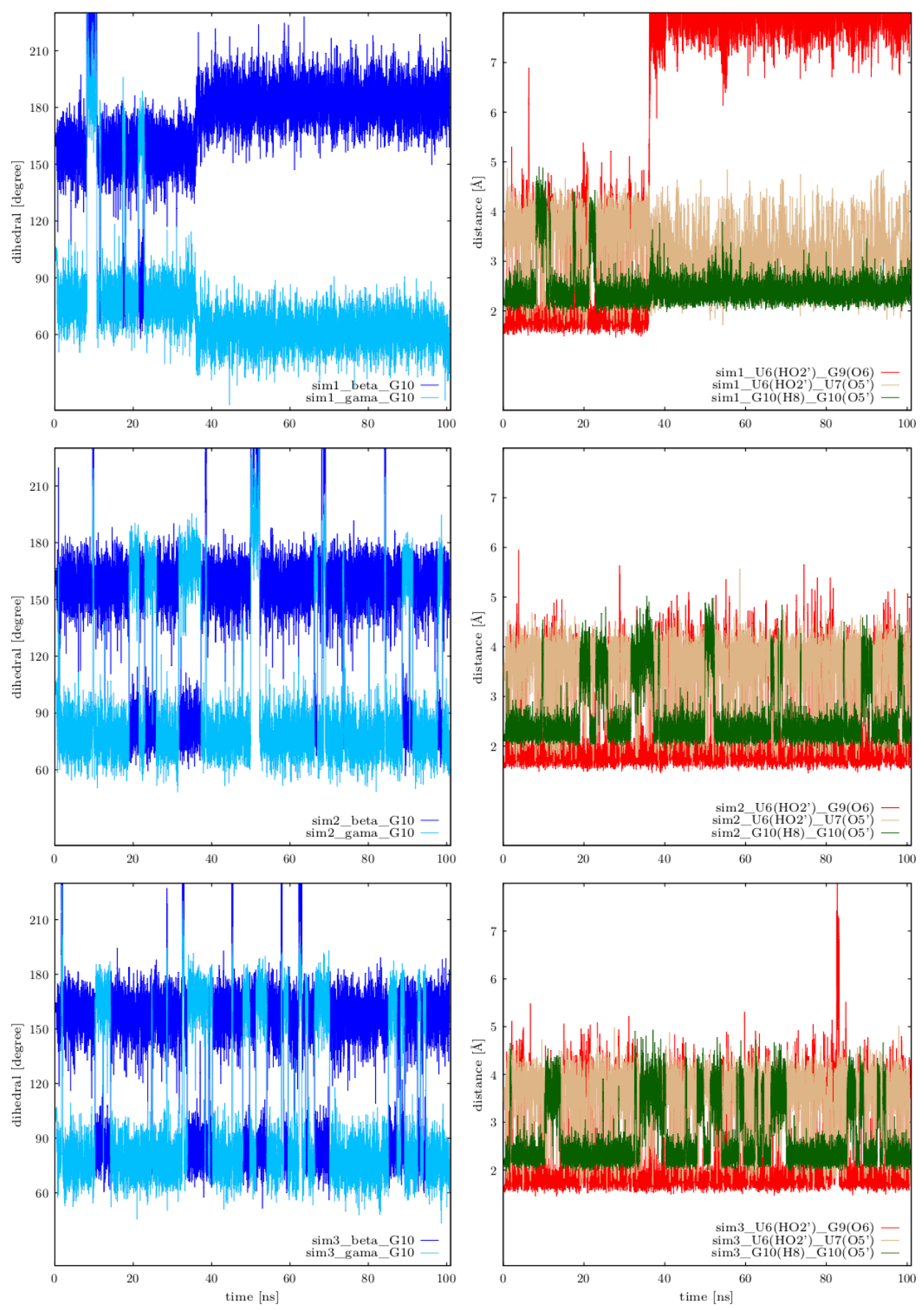

Figure S17. Occurrence of the alternative (flipped) $\mathrm{G}_{\mathrm{S}+1}$ phosphate state in three $100 \mathrm{~ns}-\mathrm{long}$ MD simulations of the r(ggcacUUCGgugcc) 14-mer and its possible correlation with the $\mathrm{U}_{\mathrm{L} 2}\left(2^{\prime}\right.$ '$\mathrm{OH}$ ) flipping. The sum of vdW radii between $\mathrm{H} 8$ atoms of all purine bases and O5' oxygens of phosphates was decreased by $0.25 \AA$ in these simulations using NBfix (see the main text). Native state of the $\mathrm{G}_{\mathrm{S}+1}$ phosphate is described by $\beta_{\text {trans }} / \gamma_{g^{+}}$dihedrals (left panels) and the $0 \mathrm{BPh}$ interaction is monitored by the distance between $\mathrm{G}_{\mathrm{S}+1}(\mathrm{C} 8 \mathrm{H} 8)$ and $\mathrm{G}_{\mathrm{S}+1}(\mathrm{O} 5$ ') atoms, i.e., the $0 \mathrm{BPh}$ interaction is present if the $\mathrm{G}_{\mathrm{S}+1}(\mathrm{C} 8 \mathrm{H} 8) \ldots \mathrm{G}_{\mathrm{S}+1}\left(\mathrm{O} 5^{\prime}\right)$ distance is below $2.5 \AA$ (panels on the right, green). Note that $\mathrm{G}_{\mathrm{L} 4}$ and $\mathrm{G}_{\mathrm{S}+1}$ are labeled as $\mathrm{G} 9$ and $\mathrm{G} 10$ in the panels. $\mathrm{G}_{\mathrm{L} 4}$ left its binding pocket just after $\sim 36 \mathrm{~ns}$ in simulation 1 ( $\operatorname{sim} 1)$. 

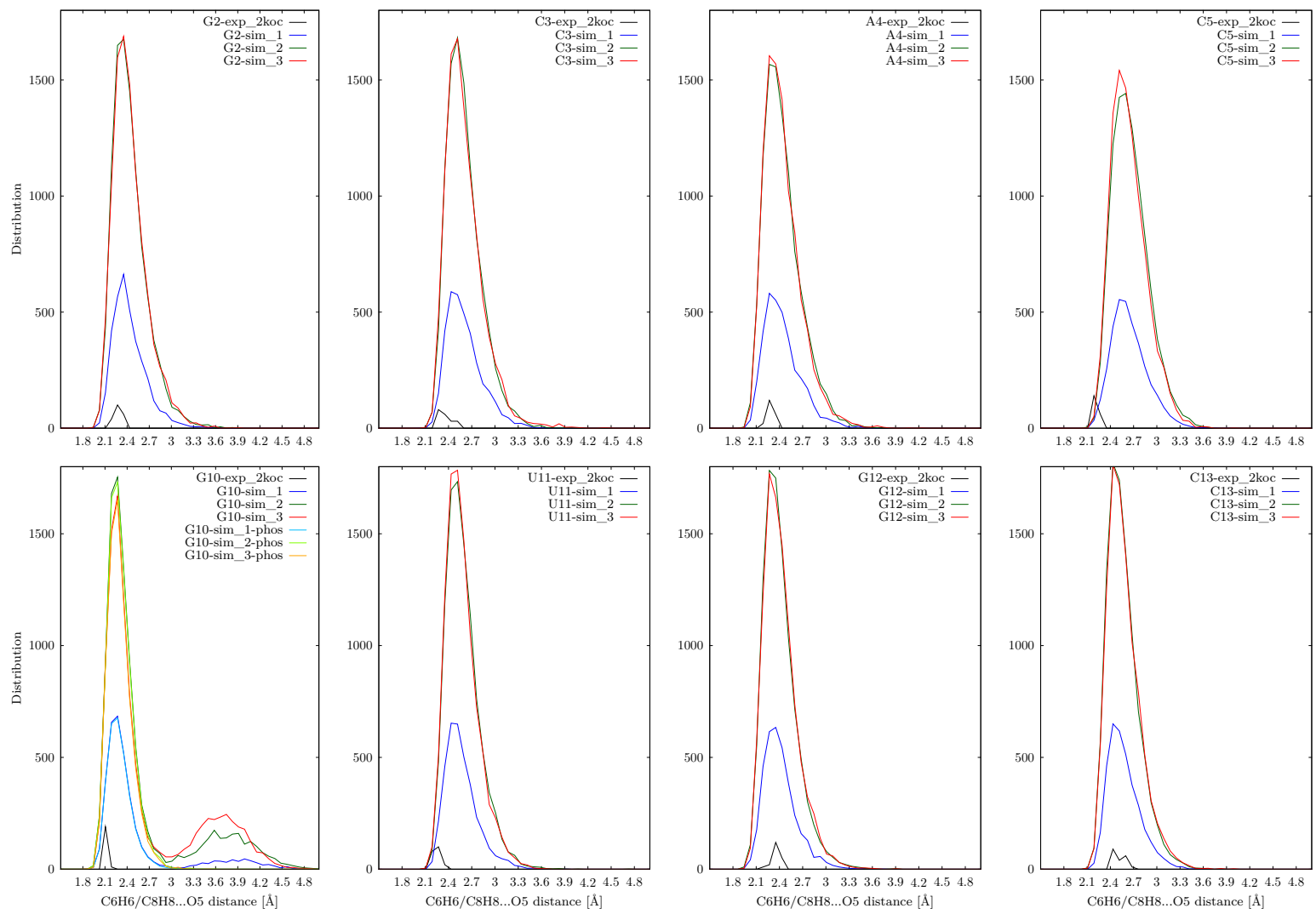

Figure S18. Distribution of C8H8/C6H6... O5' distances (0BPh interaction) in three $100 \mathrm{~ns}-$ long MD simulations with NBfix correction applied to the $-\mathrm{C} 8 \mathrm{H} 8 \ldots \mathrm{O} 5$ '- pair of the $0 \mathrm{BPh}$ interaction as described in the main text. Note that the NBfix correction is shifting the histogram for $\mathrm{G}_{\mathrm{S}+1}$ (labeled as G10 in bottom left panel) towards lower values of the $\mathrm{G}_{\mathrm{S}+1}(\mathrm{C} 8 \mathrm{H} 8) \ldots \mathrm{G}_{\mathrm{S}+1}\left(\mathrm{O} 5^{\prime}\right)$ distance when compared to Figure S4. There are two states observed for $\mathrm{G}_{\mathrm{S}+1}$ (first column, second row; $\mathrm{G}_{\mathrm{S}+1}$ is labelled as G10 in the bottom left panel) corresponding to native and flipped $\mathrm{G}_{\mathrm{S}+1}$ phosphate, i.e., presence or absence of the $0 \mathrm{BPh}$ interaction, respectively. Distributions considering only snapshots with the native $\mathrm{G}_{\mathrm{S}+1}$ phosphate conformation are colored as light blue, light green and orange for $\operatorname{sim} 1, \operatorname{sim} 2$ and $\operatorname{sim} 3$, respectively (bottom left panel, curves marked as "...-phos"). Black lines show distributions in the experimental structure (20 NMR models, PDB ID 2KOC). PDB (2KOC) numbering of nucleotides from 1 to 14 is used in the panels. 


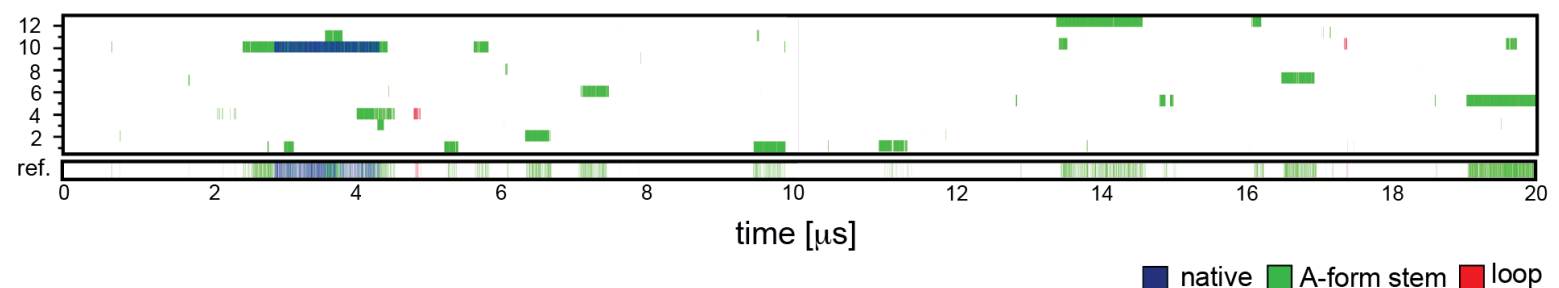

Figure S19. Conformational sampling and convergence of REST2 folding simulation of the $\mathrm{r}\left(\mathrm{gcUUCG}\right.$ Cg) TL with the gHBfix $\mathrm{UNCG}_{19}$ correction. Panel shows time evolution of major conformers, i.e., (i) correctly folded A-form stem and loop (native states with all signature interactions formed, blue), (ii) folded A-form stem (loop not in native conformation, green), and (iii) correctly folded loop (stem not in A-form, red), within all twelve continuous (demultiplexed) trajectories and the reference replica.

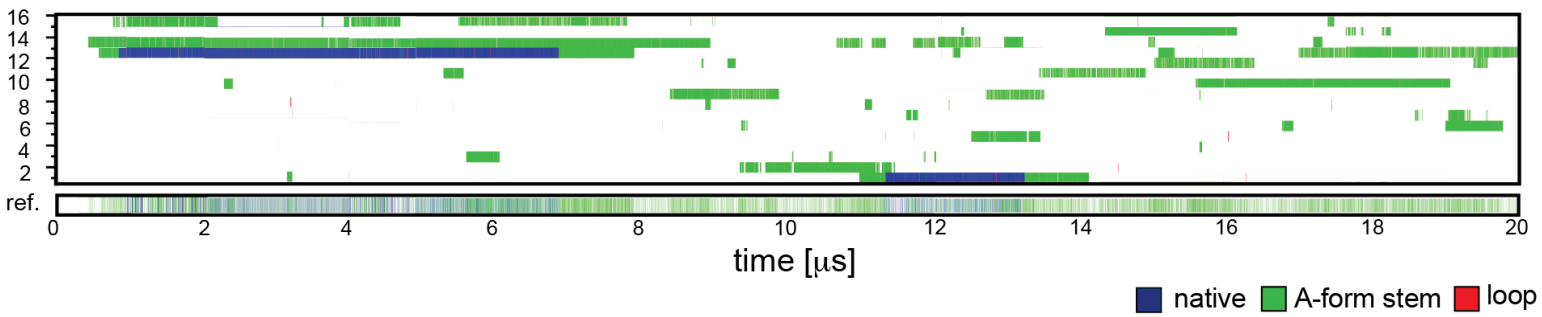

Figure S20. Conformational sampling and convergence of REST2 folding simulation of the $\mathrm{r}$ (gcUUCGgc) TL with the gHBfix ${ }_{\mathrm{UNCG}} 19$ correction in combination with NBfix correction applied on the $-\mathrm{H} 8 \ldots \mathrm{O} 5$ ' - pair of the $0 \mathrm{BPh}$ interaction. In addition, we reduced vdW radii of all non-polar $\mathrm{H}$ atoms (H1, H4, H5 and HA atoms) to $1.2 \AA$ (see the main text). Panel shows time evolution of major conformers, i.e., (i) correctly folded A-form stem and loop (native states with all signature interactions formed, blue), (ii) folded A-form stem (loop not in native conformation, green), and (iii) correctly folded loop (stem not in A-form, red), within all sixteen continuous (demultiplexed) trajectories and the reference replica. Total population of the native state in the reference replica is $\sim 7 \%$, which is still not sufficient in comparison with what is expected from experiments $(\sim 25 \%) .{ }^{30-32}$ 


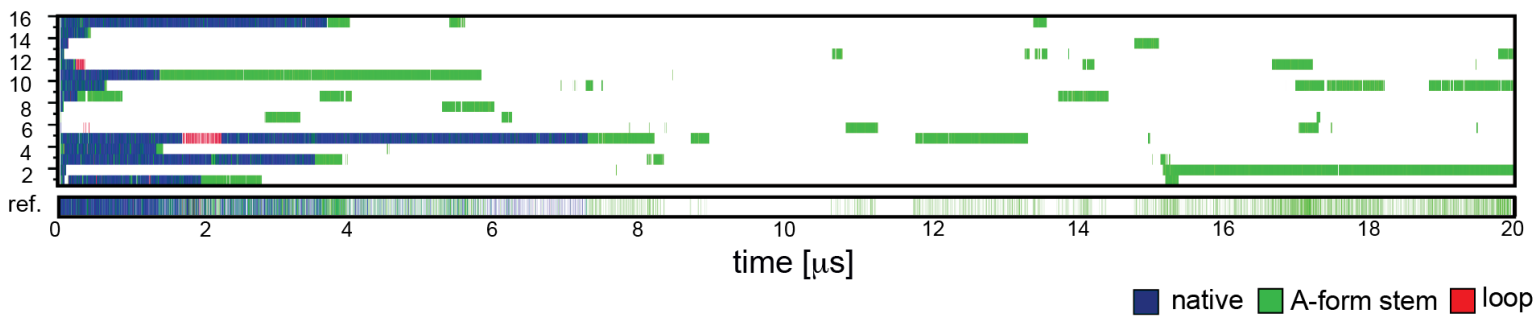

Figure S21. Conformational sampling and convergence from REST2 unfolding simulation of the $\mathrm{r}(\mathrm{gcUUUC} C \mathrm{Gg})$ TL. All replicas were started from the native state. We applied the gHBfix ${ }_{\text {UNCG19 }}$ correction in combination with NBfix correction to the $-\mathrm{H} 8 \ldots \mathrm{O}$.. - pair of the $0 \mathrm{BPh}$ interaction. We also reduced vdW radii of all non-polar $\mathrm{H}$ atoms $(\mathrm{H} 1, \mathrm{H} 4, \mathrm{H} 5$ and $\mathrm{HA}$ atoms) to $1.2 \AA$ and support the native $\mathrm{U}_{\mathrm{L} 1}\left(2^{\prime}-\mathrm{OH}\right) \ldots \mathrm{G}_{\mathrm{L} 4}(\mathrm{O} 6) \mathrm{H}$-bond by restraining the $\mathrm{U}_{\mathrm{L} 1}(\mathrm{C} 1$ '-C2'-O2'-HO2') dihedrals (see main text). Panel shows time evolution of major conformers, i.e., (i) correctly folded A-form stem and loop (native states with all signature interactions formed, blue), (ii) folded A-form stem (loop not in native conformation, green), and (iii) correctly folded loop (stem not in A-form, red), within all sixteen continuous (demultiplexed) trajectories and the reference replica. The native state was lost in all replicas after $\sim 7.5 \mu$ s despite all the restraints and corrections, indicating that the dihedral restraint (which was applied to all nucleotides) rather deteriorated the simulation, cf. with Figure S20. 


\section{S14. REFERENCES}

1. Berendsen, H. J. C., Postma, J. P. M., Van Gunsteren, W. F., Dinola, A. \& Haak, J. R. Molecular dynamics with coupling to an external bath. J. Chem. Phys. 81, 3684-3690 (1984).

2. Klamt, A. \& Schuurmann, G. COSMO: a new approach to dielectric screening in solvents with explicit expressions for the screening energy and its gradient. J. Chem. Soc., Perkin Trans. 2 799-805 (1993) doi:10.1039/P29930000799.

3. Hawkins, G. D., Cramer, C. J. \& Truhlar, D. G. Pairwise solute descreening of solute charges from a dielectric medium. Chem. Phys. Lett. 246, 122-129 (1995).

4. Hawkins, G. D., Cramer, C. J. \& Truhlar, D. G. Parametrized models of aqueous free energies of solvation based on pairwise descreening of solute atomic charges from a dielectric medium. J. Phys. Chem. 100, 19824-19839 (1996).

5. Kruse, H. Xopt. https://github.com/hokru/xopt (development version) (2017).

6. Kruse, H. \& Sponer, J. Towards biochemically relevant QM computations on nucleic acids: controlled electronic structure geometry optimization of nucleic acid structural motifs using penalty restraint functions. Phys. Chem. Chem. Phys. 17, 1399-1410 (2015).

7. Ahlrichs, R., Bär, M., Häser, M., Horn, H. \& Kölmel, C. Electronic structure calculations on workstation computers: The program system turbomole. Chem. Phys. Lett. 162, 165169 (1989).

8. TURBOMOLE. V7.1, a development of University of Karlsruhe and Forschungszentrum Karlsruhe GmbH, 1989-2007, TURBOMOLE GmbH, since 2007; available from http://www.turbomole.com. (2018).

9. Case, D. A. et al. Amber14. University of California, San Francisco (2014) doi:10.1007/s 13398-014-0173-7.2.

10. Kruse, H. BrnoFF. https://github.com/hokru/BrnoFF (2017).

11. Frisch, M. J. et al. Gaussian 09, Revision D.01. Gaussian Inc. Wallingford CT (2013).

12. Bayly, C. I., Cieplak, P., Cornell, W. D. \& Kollman, P. A. A well-behaved electrostatic potential based method using charge restraints for deriving atomic charges: The RESP model. J. Phys. Chem. 97, 10269-10280 (1993).

13. Wang, J., Wang, W., Kollman, P. A. \& Case, D. A. Automatic atom type and bond type perception in molecular mechanical calculations. J. Mol. Graph. Model. 25, 247-260 (2006).

14. Kruse, H., Mrazikova, K., D’Ascenzo, L., Sponer, J. \& Auffinger, P. Short but Weak: The Z-DNA Lone-Pair $\cdots \pi$ Conundrum Challenges Standard Carbon Van der Waals Radii. Angew. Chemie - Int. Ed. 59, 16553-16560 (2020).

15. Mladek, A. et al. Energies and 2'-hydroxyl group orientations of RNA backbone conformations. Benchmark CCSD(T)/CBS database, electronic analysis, and assessment of DFT methods and MD simulations. J. Chem. Theory Comput. 10, 463-480 (2014).

16. Richardson, J. S. et al. RNA backbone: consensus all-angle conformers and modular string nomenclature (an RNA Ontology Consortium contribution). RNA 14, 465-81 (2008).

17. Klein, D. J., Schmeing, T. M., Moore, P. B. \& Steitz, T. A. The kink-turn: a new RNA secondary structure motif. EMBO J. 20, 4214-4221 (2001).

18. Kuhrova, P. et al. Improving the Performance of the Amber RNA Force Field by Tuning the Hydrogen-Bonding Interactions. J. Chem. Theory Comput. 15, 3288-3305 (2019). 
19. Reblova, K., Sponer, J. E., Spackova, N., Besseova, I. \& Sponer, J. A-minor tertiary interactions in RNA kink-turns. Molecular dynamics and quantum chemical analysis. $J$. Phys. Chem. B 115, 13897-13910 (2011).

20. Krepl, M., Reblova, K., Koca, J. \& Sponer, J. Bioinformatics and molecular dynamics simulation study of L1 stalk non-canonical rRNA elements: kink-turns, loops, and tetraloops. J. Phys. Chem. B 117, 5540-5555 (2013).

21. Sponer, J., Riley, K. E. \& Hobza, P. Nature and magnitude of aromatic stacking of nucleic acid bases. Phys. Chem. Chem. Phys. 10, 2595-2610 (2008).

22. Zgarbova, M., Otyepka, M., Sponer, J., Hobza, P. \& Jurecka, P. Large-scale compensation of errors in pairwise-additive empirical force fields: Comparison of AMBER intermolecular terms with rigorous DFT-SAPT calculations. Phys. Chem. Chem. Phys. 12, 10476-10493 (2010).

23. Kruse, H., Banas, P. \& Sponer, J. Investigations of stacked DNA base-pair steps: Highly accurate stacking interaction energies, energy decomposition, and many-body stacking effects. J. Chem. Theory Comput. 15, 95-115 (2019).

24. Szabla, R., Havrila, M., Kruse, H. \& Šponer, J. Comparative Assessment of Different RNA Tetranucleotides from the DFT-D3 and Force Field Perspective. J. Phys. Chem. B 120, 10635-10648 (2016).

25. Nozinovic, S., Fürtig, B., Jonker, H. R. A., Richter, C. \& Schwalbe, H. High-resolution NMR structure of an RNA model system: The 14-mer cUUCGg tetraloop hairpin RNA. Nucleic Acids Res. 38, 683-694 (2009).

26. Tan, D., Piana, S., Dirks, R. M. \& Shaw, D. E. RNA force field with accuracy comparable to state-of-the-art protein force fields. Proc. Natl. Acad. Sci. U. S. A. 115, E1346-E1355 (2018).

27. Kuhrova, P. et al. Correction to: Improving the Performance of the Amber RNA Force Field by Tuning the Hydrogen-Bonding Interactions. J. Chem. Theory Comput. 16, 818819 (2020).

28. Pokorna, P., Kruse, H., Krepl, M. \& Sponer, J. QM/MM Calculations on Protein-RNA Complexes: Understanding Limitations of Classical MD Simulations and Search for Reliable Cost-Effective QM Methods. J. Chem. Theory Comput. 14, 5419-5433 (2018).

29. Steinbrecher, T., Latzer, J. \& Case, D. A. Revised AMBER parameters for bioorganic phosphates. J. Chem. Theory Comput. 8, 4405-4412 (2012).

30. Sheehy, J. P., Davis, A. R. \& Znosko, B. M. Thermodynamic characterization of naturally occurring RNA tetraloops. RNA 16, 417-429 (2010).

31. Mathews, D. H. et al. Incorporating chemical modification constraints into a dynamic programming algorithm for prediction of RNA secondary structure. Proc. Natl. Acad. Sci. U. S. A. 101, 7287-7292 (2004).

32. Abdelkafi, M. et al. Common structural features of uucg and uacg tetraloops in very short hairpins determined by uv absorption, raman, ir and nmr spectroscopies. J. Biomol. Struct. Dyn. 14, 579-593 (1997). 